\title{
EBR-II NOISE-SIGNATURE ANALYSIS DURING THE FIRST HALF \\ OF FISCAL YEAR 1971
}

by

C. C. Price and J. R. Karvinen

\author{
EBR-II Project \\ Argonne National Laboratory \\ Argonne, Illinois - Idaho Falls, Idaho
}

February 1971

This report was prepared as an account of work sponsored by the United States Government. Neither the United States nor the United States Atomic Energy Commission, nor any of their employees, nor any of their contractors, subcontractors, or their employees, makes any warranty, express or implied, or assumes any legal liability or responsibility for the accuracy, completeness or usefulness of any information, apparatus, product or process disclosed, or represents that its use would not infringe privately owned rights.

Work performed under the auspices of the U. S. Atomic Energy Commission. 


\section{DISCLAIMER}

This report was prepared as an account of work sponsored by an agency of the United States Government. Neither the United States Government nor any agency Thereof, nor any of their employees, makes any warranty, express or implied, or assumes any legal liability or responsibility for the accuracy, completeness, or usefulness of any information, apparatus, product, or process disclosed, or represents that its use would not infringe privately owned rights. Reference herein to any specific commercial product, process, or service by trade name, trademark, manufacturer, or otherwise does not necessarily constitute or imply its endorsement, recommendation, or favoring by the United States Government or any agency thereof. The views and opinions of authors expressed herein do not necessarily state or reflect those of the United States Government or any agency thereof. 


\section{DISCLAIMER}

Portions of this document may be illegible in electronic image products. Images are produced from the best available original document. 
-

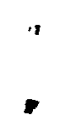


TABLE OF CONTENTS

Page

ABSTRACT

I. INTRODUCTION 9

II. SEARCH FOR THE "10-Hz" NOISE 10

III. SIGNATURES RELATED TO APPARENT PUMP BINDING 11

IV. SIGNATURES RELATED TO UNUSUAL NOISE IN THE INTERMEDIATE HEAT EXCHANGER

APPENDIXES

A. Disturbance on Primary-sodium Pump No. 1 on September 24, 1970

B. Noise Monitoring of the Intermediate Heat Exchanger

C. Calculation of Vibrations of IHX Drain Tube 
- 


\section{LIST OF FIGURES}

No.

$\underline{\text { Title }}$

$\underline{\text { Page }}$

1. Flow-dependence of Low-frequency Neutron Fluctuations in EBR-II： Power, $50 \mathrm{~kW}$. . . . . . . . . . . . . 12

2. Power-dependence of Low-frequency Neutron Fluctuations in EBR-II: 100\% of Full Flow. ................ 13

3. Signatures of Primary-sodium Pump No. 1 before and after Scram and of Primary-sodium Pump No. 2 after Scram. . . . . . . 14

4. Uneven Buildup of Sodium Oxide on Shaft above Labyrinth Seal of Primary-sodium Pump No. 1 . . . . . . . . . . . 15

5. Copper Plating of Shaft of Primary-sodium Pump No. 1 Caused by Deterioration of Labyrinth Seal . . . . . . . . . . . . 16

6. Configuration of IHX Secondary-sodium Inlet Pipe and Drain Tube. . . . . . . . . . . . . . . . . 18

7. Resonances of IHX Drain Tube with Sodium Drained and Both J-clips Removed . . . . . . . . . . . . . . . . 19

8. Measured Resonances of IHX Drain Tube with Sodium Drained and Both J-clips Removed. (Measured by Accelerometer on Drain Tube) . . . . . . . . . . . . . . . . . . 20

9. Resonances of IHX Drain Tube Immersed In Sodium, with Upper J-clip in Place and Lower J-clip Removed. . . . . . . . . 22

10. Noise Spectra of IHX Drain Tube at Various Secondary Flows, as Recorded by Accelerometer on Drain Tube on November 17, 1970. 23

11. Transient Capture of Actual IHX Noise at $79 \%$ Secondary Flow When Only the Accelerometer on the Inlet-pipe Thermocouple Well Was Excited by the Noise. . . . . . . . . . . 25

12. Transient Capture of Actual IHX Noise at $79 \%$ Secondary Flow When the Accelerometers on the Drain Tube and on the Inlet-pipe Thermocouple Well Both Were Excited by the Noise. . . . . . 26

13. Noise Produced by Ball-bearing Generator Hitting 18.5 in. above Grid Plate of IHX, as Recorded by Accelerometer on Inlet-pipe Thermocouple Well . . . . . . . . . . . . . . . 27

14. Verification of Spectrum Analysis of IHX Flow Noise with the Digital Data Acquisition System . . . . . . . . . . 28 


\section{LIST OF FIGURES (contd)}

No.

$\underline{\text { Title }}$

$\underline{\text { Page }}$

A-1 These are untitled plots of noise spectra related to a dis-

through turbance on primary-sodium pump No. 1 on September 29, 1970 . 31-36

A-6.

B-1. Locations of Accelerometers and Microphone for Monitoring IHX Noise in November 1970. . . . . . . . . . . . . 43

B-2. Data from Roving Accelerometer (position b, direction $x$, Fig. B-1) on IHX Drain Tube at Constant Primary Flow and Various Secondary Flows . . . . . . . . . . . . . . . 44

B-3. Data from Reference Accelerometer (position a, Fig. B-1) at Constant Primary Flow and Various Secondary Flows . . . . . 45

B-4. Data from Roving Accelerometer (position b, direction $x$, Fig. B-1) at Constant Secondary Flow and Various Primary flows .. . . . . . . . . . . . . . . . 446

B-5. Low-frequency Spectra from Accelerometer on Drain Tube (position b, Fig. B-1). . . . . . . . . . . . . 4 47

B-6. Low-frequency Spectra from Accelerometer on IHX Secondarysodium Inlet Pipe (position a, Fig. B-1). . . . . . . . . 48

B-7. Noise Registered by Reference Accelerometer, but Not by Roving Accelerometer on Drain Tube . . . . . . . . . . . . . 49

B-8. Noise Registered Both by Reference Accelerometer and by Roving Accelerometer on Drain Tube . . . . . . . . . . . 50

B-9. Noise Spectra during Shutdown of Reactor on November 14, 1970 (position a, Fig. B-1)................. 51

B-10. Noise on IHX Inlet and Outlet Pipes on November 14, 1970, and on Outlet Pipe on August 21, 1970 . . . . . . . . . . . 52

B-11. Comparison of Noise Burst and Averaged Noise Spectra from IHX . 53 


\section{TABLE}

No.

Title

Page

I. Comparison of Calculated and Measured Resonances of Drain Tube When IHX Is Filled with Sodium. . . . . . . . . . . . . 24 
•

• 
EBR-II NOISE-SIGNATURE ANALYSIS DURING THE FIRST HALF

OF FISCAL YEAR 1971

by

C. C. Price and J. R. Karvinen

ABSTRACT

This report is a chronology of the noise-signature analysis done to date (February 1971) on EBR-II and its auxiliary systems. This effort began with a search for the source of the "10-Hz" noise present in the ionchamber signals. The search provided a signature of primary-sodium pump No. 1 which could be compared with the signature after an apparent binding of the pump. The comparison indicated more-eccentric rotation of the pump after the apparent binding. The cause was apparently failure of the lower labyrinth seal. On November 4, 1970, an unusual noise was discovered emanating from the intermediate heat exchanger (IHX). A signature obtained on the secondary-sodium outlet pipe of the IHX on August 21, 1970, had not shown any unusual noise present. Further signature-analysis work, described herein with preliminary results, helped identify the cause of the noise.

\section{INTRODUCTION}

Noise analysis--also called signature analysis or noise-signature analysis ${ }^{l}-$ is the work of monitoring the various sources of energy emission from an operating machine or system to determine its "physical" condition.

Generally, a passive transducer is used to detect the energy emission. Because the emission usually contains some randomness and often many sinusoidal components, it is called "noise." The term "signature" is used because systems emit "noise" that is characteristic (is a "signature") of the system and its physical condition. This signature identifies the system, much as the hand-written signature identifies a man. 
The signatures can be used in several ways. ${ }^{2}$ One is for calculating the expected emission characteristics of a system and for searching the frequency spectrum for them. A simple case could be the calculation and measurement of the vibrational frequencies of a beam. A second way is to examine the signature, often in the frequency domain, and evaluate it from previous empirical knowledge. The third and probably most common use is to obtain and store the signature of a system known to be operating properly (or improperly) and then use this signature as a standard against which to compare signatures obtained at other times or under other conditions. By use of this comparison technique, trends can be observed, and incipient failures can be predicted in many cases.

A good example is the situation where a ball bearing is monitored throughout its life. When the bearing is new and in its best condition, the energy emitted is at a minimum. As the bearing wears and becomes looser, the amount of energy emitted by the bearing increases as a function of wear. If a race should crack or if spalling should set in, the noise emitted from the bearing would increase sharply and be characteristic of the defect.

Early in fiscal year 1971, efforts were started to obtain noise signatures of EBR-II and its auxiliary systems. This report briefly describes those efforts and what they have accomplished in six months.

\section{SEARCH FOR THE "10-Hz" NOISE}

The initial efforts in noise-signature analysis of EBR-II and its auxiliary systems were directed toward the "10-Hz" noise present in the ion-chamber signals during reactor operation from $50 \mathrm{~kW}$ through $6.2 .5 \mathrm{MWt}$.

To investigate the noise in the frequency domain, a realtime analyzer was used to reduce the noise data obtained and to provide amplitude-vsfrequency (Fourier spectrum) and power-vs-frequency (power spectrum) plots of the noise records. One magnetically mounted and three mechanically mounted accelerometers were placed in various locations about the reactor. Records from these were made simultaneously with the neutron signal to determine if the "10-Hz" signal source could be external to the reactor core. The primary pumps, shield plugs, ion-chamber thimbles, terminal box of instrumented subassembly XX02, contro1 rods, holddown fixtures, and secondary- 
sodium outlet pipe of the intermediate heat exchanger (IHX) were all monitored. Variation of primary flow affected the frequency spectrum on $n(t)$. Variation of power in 10-MWt steps also affected the spectrum on $n(t)$. Figures 1 and 2 show that the frequency (nominally called "10-Hz") does not remain constant, but shifts with changes in flow rate of the primary sodium. This shift is more pronounced than the shift caused by the power changes. Also shown is a splitting of the frequency peak at various levels of flow and power. The data displayed were taken with an ion chamber in the J-4 thimble. Frequency resolution of these spectra is $0.3 \mathrm{~Hz}$.

\section{SIGNATURES RELATED TO APPARENT PUMP BINDING}

The "10-Hz" noise was not detected external to the core. However, the search for this noise provided a signature of primary-sodium pump No. 1 before the first of several scrams apparently caused by binding of the pump. Signatures of pump Nos. 1 and 2 were taken after the scram. The signature of pump No. 1 had changed. The second harmonic had increased to about double the amplitude of the fundamental, which indicated a moreeccentric rotation of the shaft after the scram than before. Figure 3 shows the signatures of pump No. 1 before and after the scram and the signature of pump No. 2 after the scram. For pump No. 1, the second harmonic was about twice the amplitude of the fundamental at both zero power and at 50-MWt power. Before the scram, the fundamental was twice the amplitude of the second harmonic.

A disturbance on pump No. 1 also occurred on September 29, 1970. The events relative to the signature-analysis effort at the time of this disturbance are documented in Appendix A. The variation of the harmonics suggested that foreign material entered and moved periodically within the fluid bearing. Disassembly of the pump during the shutdown to investigate the noise in the IHX (see Sec. IV) showed an uneven buildup of sodium oxlde on the shaft above the labyrinth seal (see Fig. 4), which suggested that rotation had nat been concentric. The lower labyrinth seal was being progressively abraded by sodium oxide pieces falling into the serrations of the seal. During this process, exaggerated eccentric rotation would be caused as the fluid bearing allowed the shaft to move over whenever sodium oxide passed one side of the seal (see Fig. 5). 


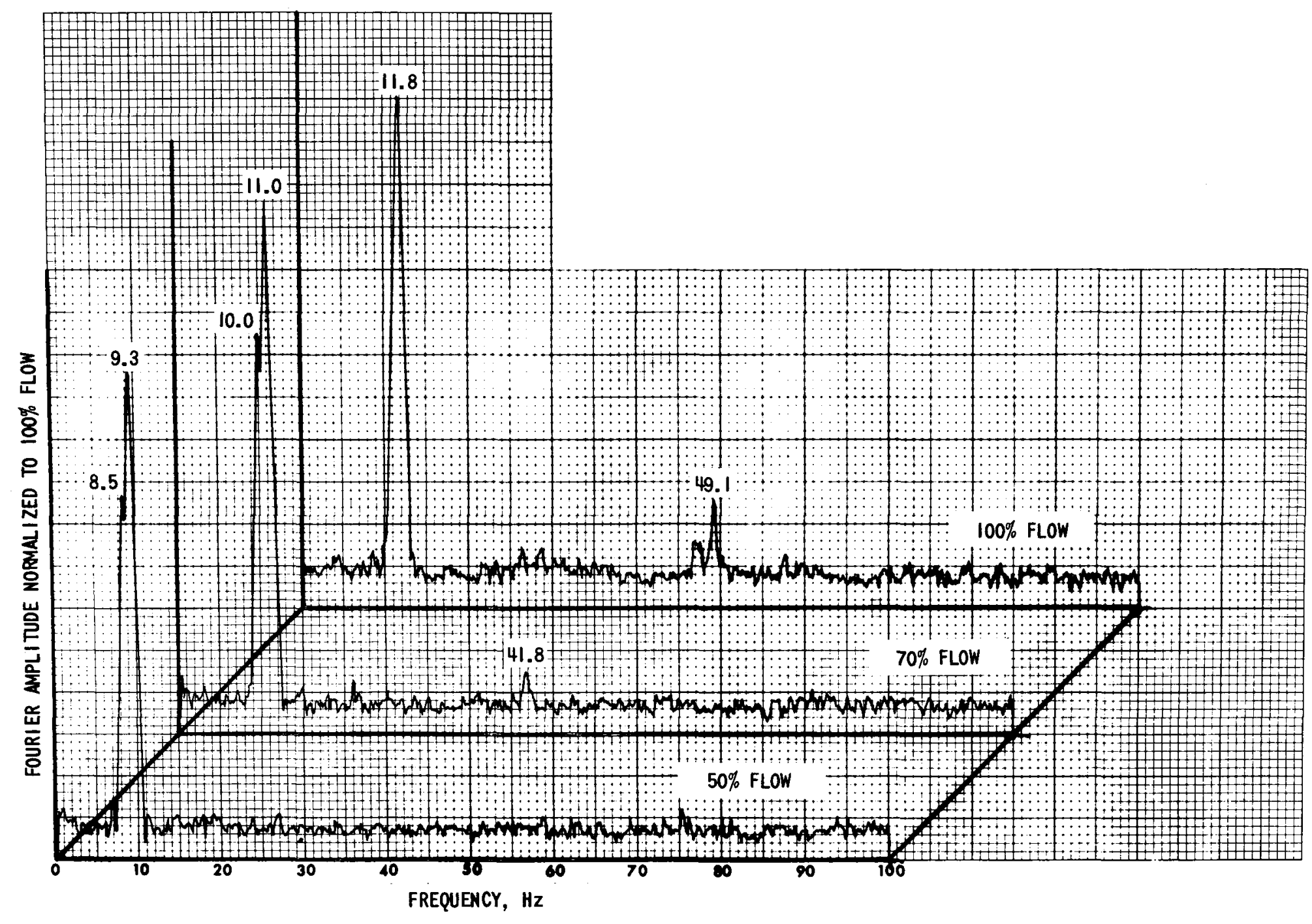

Fig. 1. Flow-dependence of Low-frequency Neutron Fluctuations in EBR-II: Power, $50 \mathrm{~kW}$ 


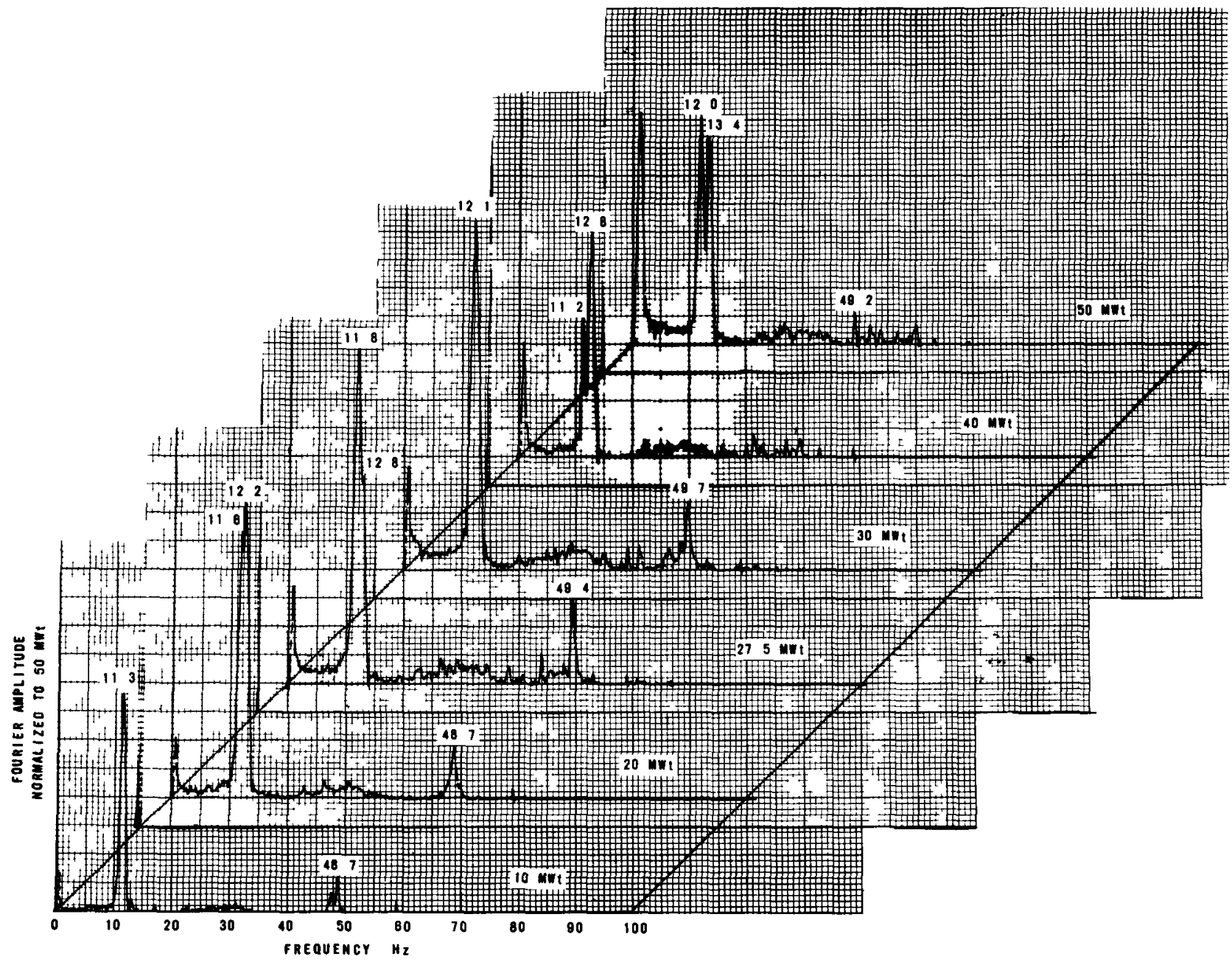

1

Fig. 2. Power-dependence of Low-frequency Neutron Fluctuations in EBR-II: $100 \%$ of Ful1 Flow 

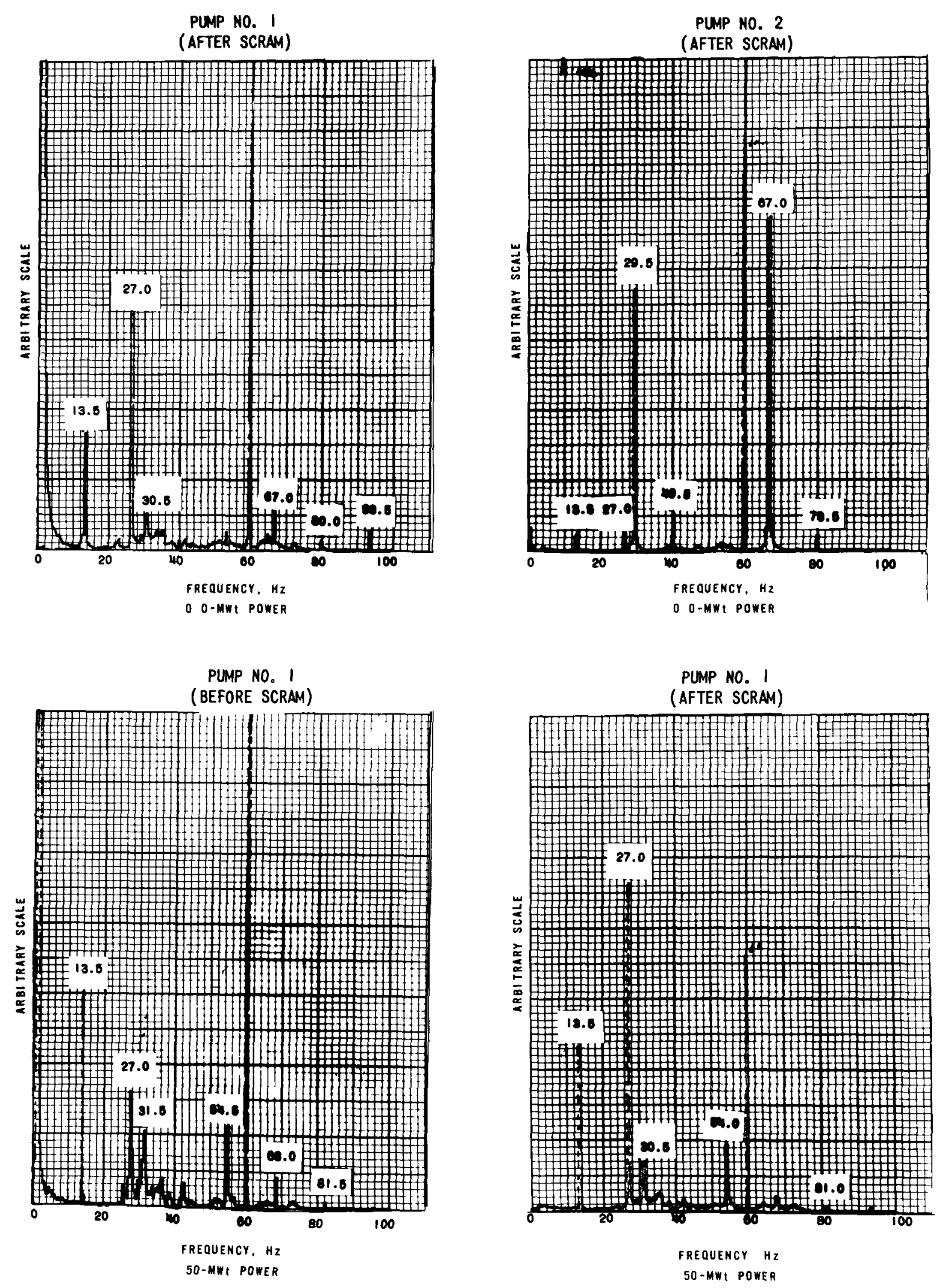

Fig. 3. Signatures of Primary-sodium Pump No. 1 before and after Scram and of Primary-sodium Pump No. 2 after Scram (upper right) 


\section{-}

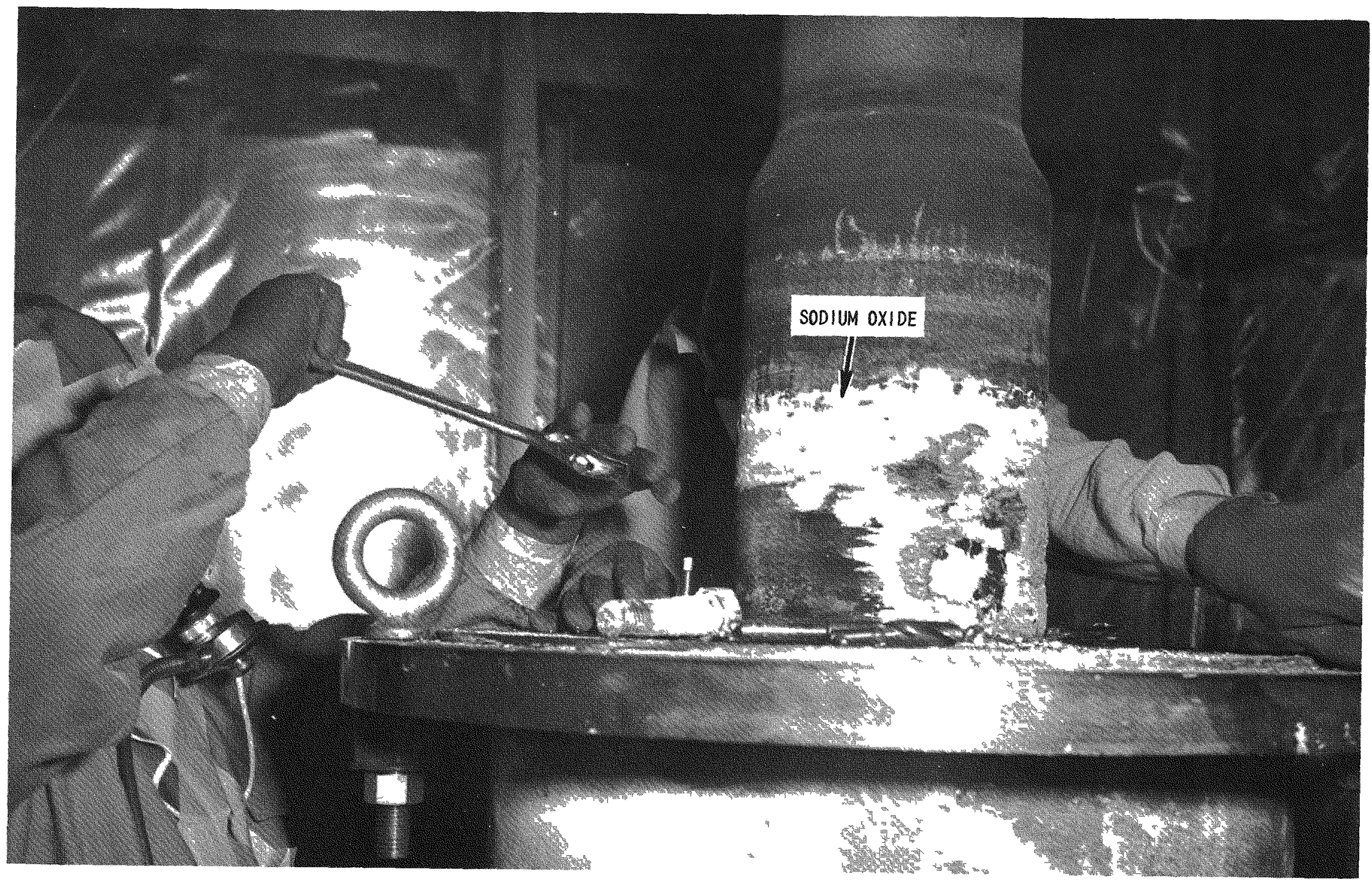

Fig. 4. Uneven Buildup of Sodium Oxide on Shaft above Labyrinth Seal of Primary-sodium Pump No. 1 


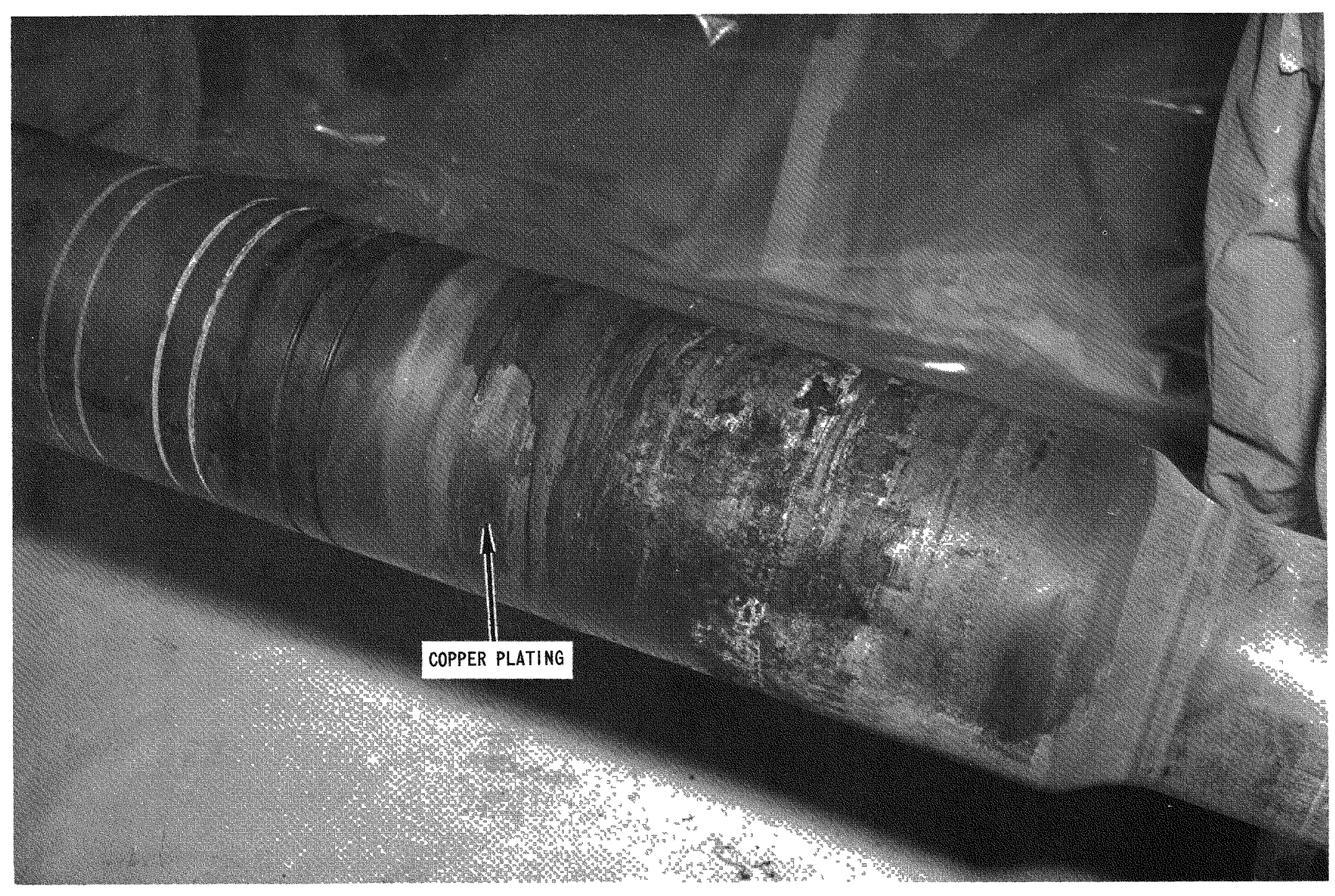

Fig. 5. Copper Plating of Shaft of Primary-sodium Pump No. 1 Caused by Deterioration of Labyrinth Seal 


\section{SIGNATURES RELATED TO UNUSUAL NOISE IN THE INTERMEDIATE HEAT EXCHANGER}

Monitoring of the auxiliary systems for the $10-\mathrm{Hz}$ source also provided a signature of the IHX. A signature obtained on August 21, 1970, with an accelerometer on the thermocouple well at the elbow of the outlet pipe of the IHX, contained only $60 \mathrm{~Hz}$ and its harmonics, and showed no appreciable unexplained noise. When an unusual audible noise was discovered emanating from the IHX on November 14, 1970, the noise spectrum was several times higher in amplitude than the 60-Hz harmonics previously recorded. This noise and the initial test program for determining its cause are discussed in Appendix B. The conclusion drawn--that the cause probably was a large loose piece rather than the stainless steel drain tube (see Fig. 6) inside the inlet pipe of the IHX--was based on the fact that the drain tube did not display the noise burst every time a burst was detected on the inlet pipe. This phenomenon is difficult to explain in light of the fact that not only visual examination, but also the subsequent testing after the IHX was opened, indicated that the drain tube was indeed the primary noise source, with the lower J-clip suspect of contributing higher-frequency perturbations. A report of these findings is being prepared. The following discussion summarizes the findings.

Analysis of the noise data (see Appendix $C$ ) taken on the IHX indicated that the drain tube was firmly attached to the stand penetrating the baffles at the bottom of the IHX. Measured resonances of the tube were compared with resonances calculated from two"models of the drain tube (see Fig. 7). In one model, the tube was fixed (firmly attached) at both ends; in the other, the tube was fixed at the top, but pinned (free to pivot) at the bottom.

For both the measurements and calculations, the sodium was drained from the IHX, and the noise was generated externally. For the calculations, both the upper and lower J-clips (which laterally support the tube) were assumed removed.

Figure 7 shows that the values calculated from the fixed-fixed model compare favorably with the measured values (shown in Fig. 8). The values calculated from the fixed-pinned model are significantly below the measured values. 


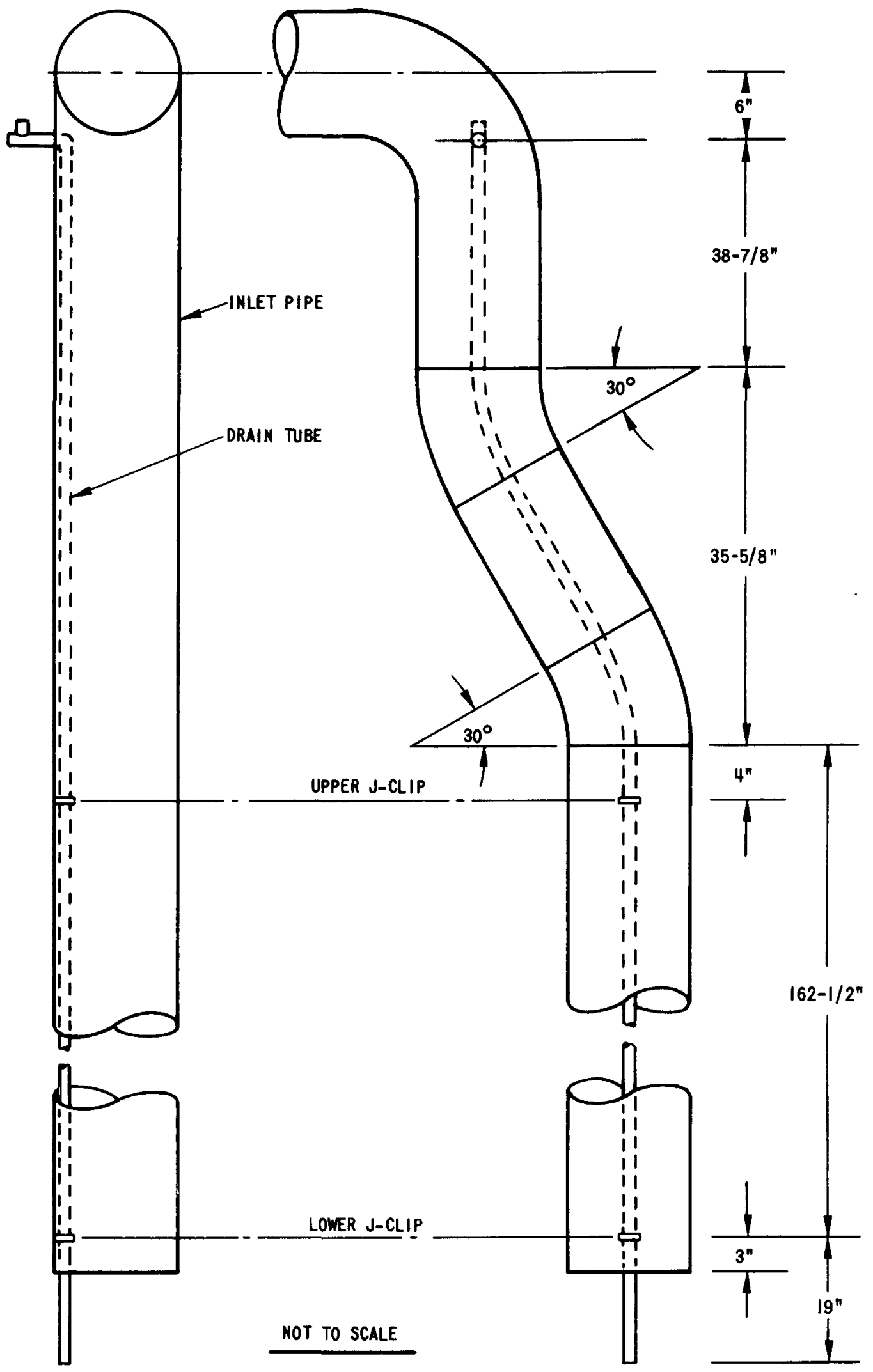

Fig. 6. Configuration of IHX Secondary-sodium Inlet Pipe and Drain Tube 

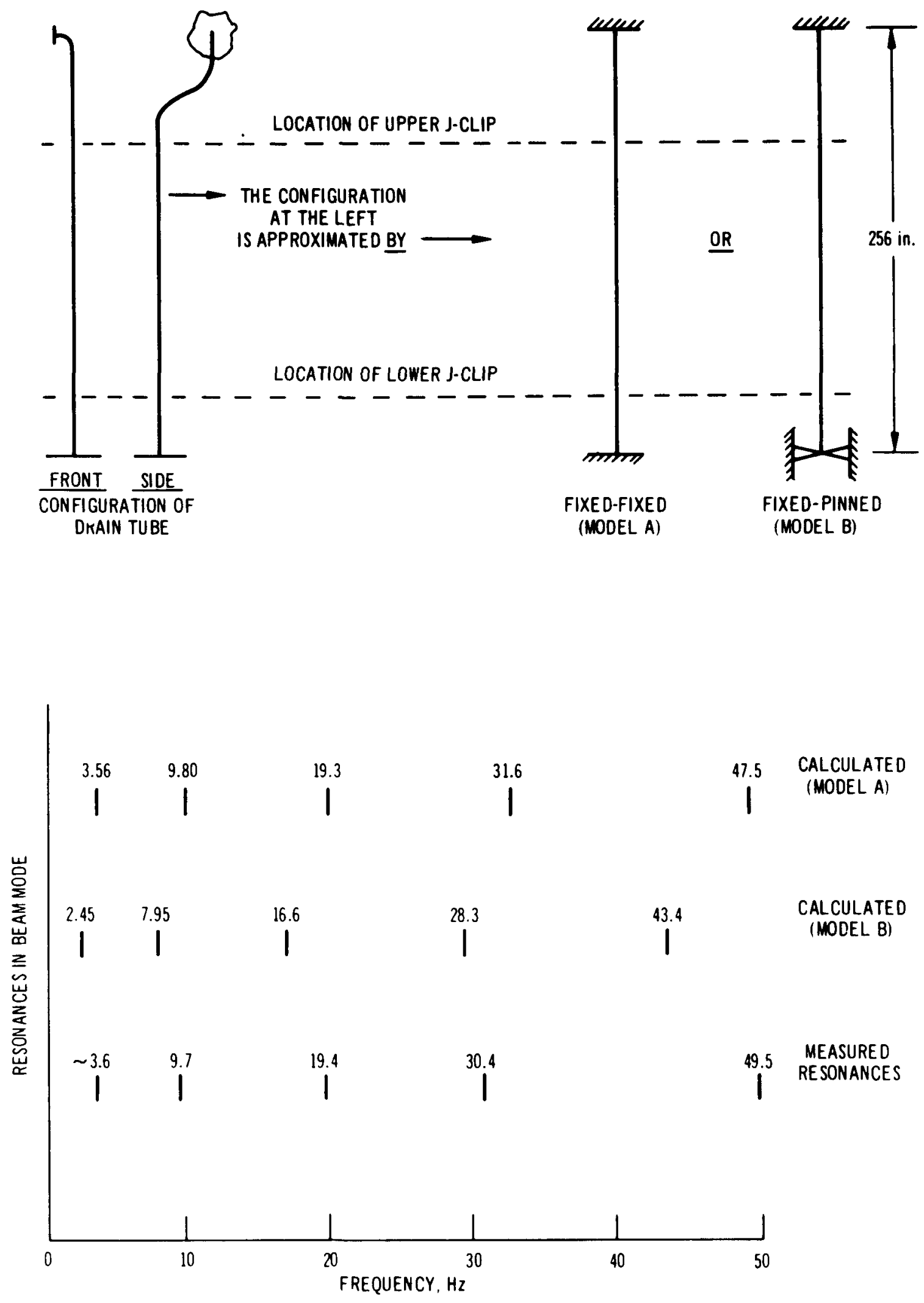

Fig. 7. Resonances of IHX Drain Tube with Sodium Drained and Both J-clips Removed 

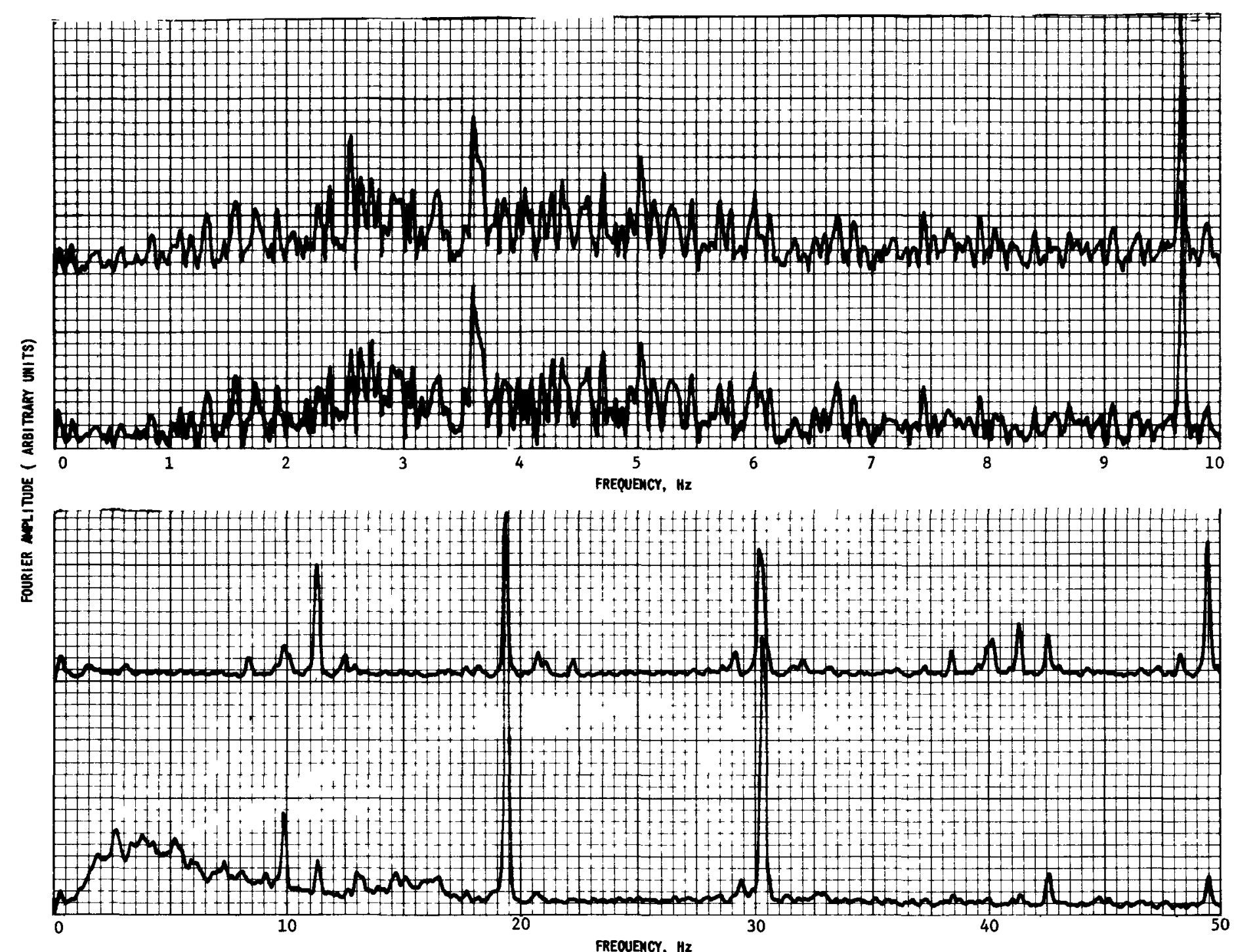

Fig, 8. Measured Resonances of IHX Drain Tube with Sodium Drained and Both J-clips Removed. (Measured by Accelerometer on Drain Tube) 
Two other models (Fig. 9) were used to estimate resonant modes of the drain tube immersed in sodium and fixed at both ends. The drain-tube motion in this case was generated by flowing sodium and random impacting on the wall of the large pipe. In one model, the tube was assumed fixed* at the upper J-clip; in the other, it was assumed pinned at the clip. The values calculated from the second model compare favorably with the data taken at the various flow levels November 17, 1970, the Monday after the unusual noises in the IHX were first noticed (see Figs. 9 and 10 and Table I).

Other spectra indicated that the drain tube was the primary noise generator. A transient capture of the noise when tt was not present on the accelerometer on the drain tube, but was present on the accelerometer on the inlet pipe (see FIg. 11), was compared with a transient capture of the noise when both accelerometers responded (Fig. 12). The noise spectra, when present on the accelerometer on the drain tube, contained one predominant frequency (about $2.6 \mathrm{kHz}$ ) that was not predominant when the noise did not appear there. Efforts to explain the cause of this phenomenon continue. It is believed that a loose upper J-clip would cause vibrations of a higher frequency. This belief is based on the noise spectra (Fig. 13) produced with a ball-bearing generator; which Indicate that a small object hitting the lower part of the inlet pipe excites the higher-frequency resonances more effectively.

The digital data acquisition system (DAS) was used to verify operation of the spectrum analyzer (see Fig. 14). Cross-correlation of signals was also attempted with the DAS. However, the same problems occurred with this attempt as with a borrowed cross-correlator, i.e., without a signature obtained with a known noise source prior to the occurrence, the correlograms were too complicated to produce any usable logic. However, once correlograms are made in the future, the DAS can be used to obtain the various transfer functions between known pehnomena within the reactor and its auxiliary systems.

\footnotetext{
* "Fixed" in the sense that a moment such as that generated by a rigidly embedded beam section was assumed. This moment was assumed to be transmitted to the upper part of the tube. In the case in which the drain tube is assumed pinned at the upper J-clip, this moment becomes zero.
} 

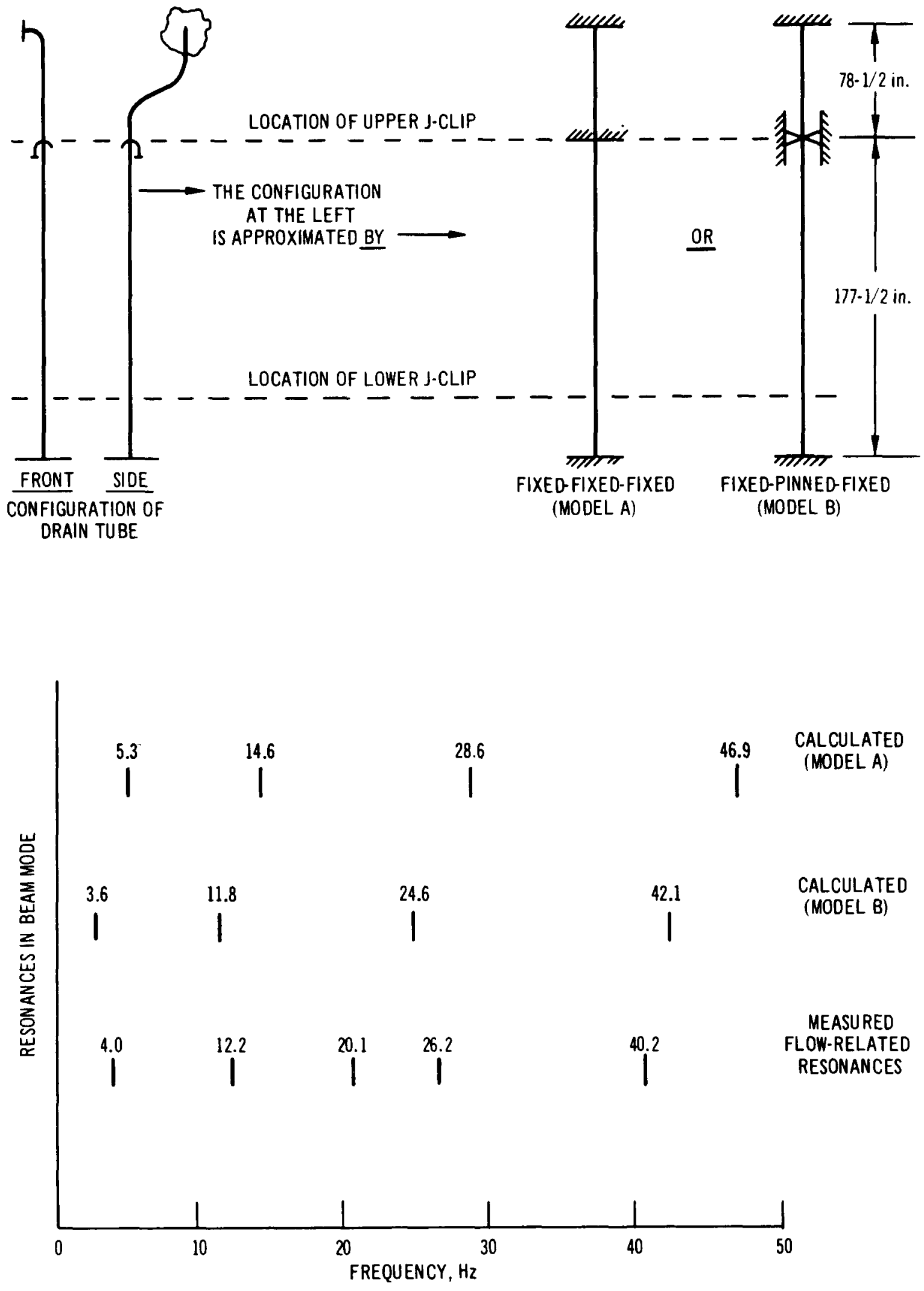

Fig. 9. Resonances of IHX Drain Tube Immersed in Sodium, with Upper J-clip in Place and Lower J-clip Removed 


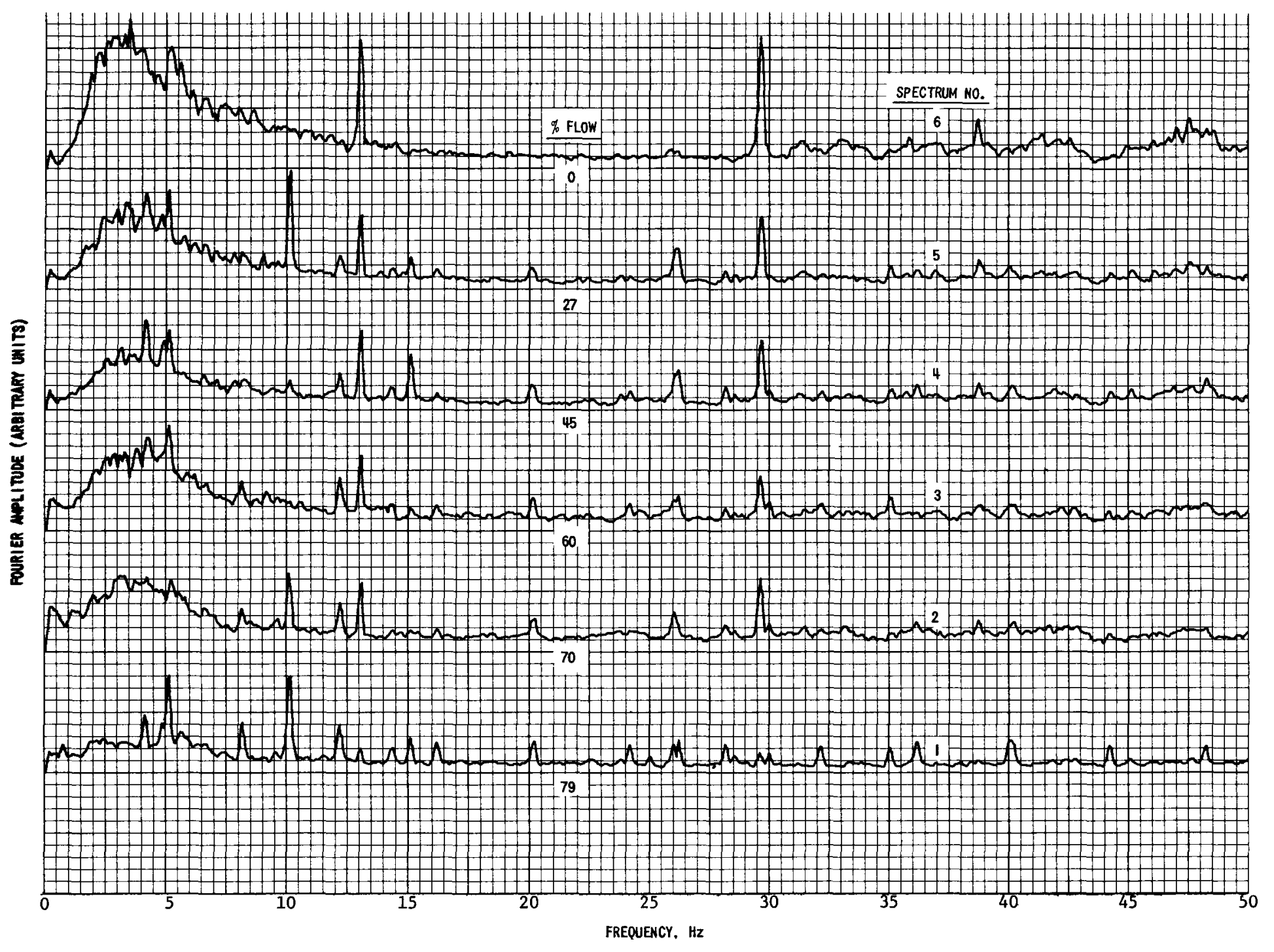

Fig. 10. Noise Spectra of IHX Drain Tube at Various Secondary Flows, as Recorded by Accelerometer on Drain Tube on November 17, 1970 
TABLE I. Comparison of Calculated and Measured Resonances of Drain Tube When IHX Is Filled with Sodium

\begin{tabular}{|c|c|c|c|c|c|c|}
\hline \multirow[b]{3}{*}{ Mode, $\mathrm{n}$} & \multicolumn{4}{|c|}{ Frequencies, $\mathrm{Hz}$} & \multirow[b]{3}{*}{ Measured } & \multirow[b]{3}{*}{ Appearance vs Flow $^{2}$} \\
\hline & \multicolumn{2}{|c|}{ Upper $78^{\frac{1}{2}}$ in. of Tube } & \multicolumn{2}{|c|}{ Lower $177 \frac{1}{2}$ in. of Tube } & & \\
\hline & Fixed-Fixed & Fixed-Pinned & Fixed-Fixed & Pinned-Fixed & & \\
\hline \multirow[t]{3}{*}{1} & 27.0 & 18.4 & 5.3 & 3.6 & 4.0 & $1,2,3,4,5$ \\
\hline & & & & & 8.1 & $1,2,3$ \\
\hline & & & & & 10.1 & $1,2,5$ \\
\hline \multirow[t]{2}{*}{2} & 74.5 & 60.4 & 14.6 & 11.8 & 12.2 & $1,2,3,4,5$ \\
\hline & & & & & 15.1 & $1,3,4$ \\
\hline \multirow[t]{4}{*}{3} & 146.0 & 125.6 & 28.6 & 24.6 & 20.1 & $1,2,3,4,5$ \\
\hline & & & & & 26.2 & $1,2,3,4,5$ \\
\hline & & & & & 35.0 & $1,3,4,5$ \\
\hline & & & & & 36.2 & 1 \\
\hline \multirow[t]{3}{*}{4} & 240.1 & 215.2 & 46.9 & 42.1 & 40.2 & $1,2,3,4,5$ \\
\hline & & & & & 44.2 & 1 \\
\hline & & & & & 48.2 & 1 \\
\hline
\end{tabular}

a Indicates the appearance of a resonance peak in the spectra for the following secondary-flow levels: $79 \%$ (1), $70 \%(2), 60 \%$ (3), 45\% (4), 27\% (5). Peaks present at 0\% flow (see Spectrum No. 6, Fig. 10) were not considered to be flow-related. 


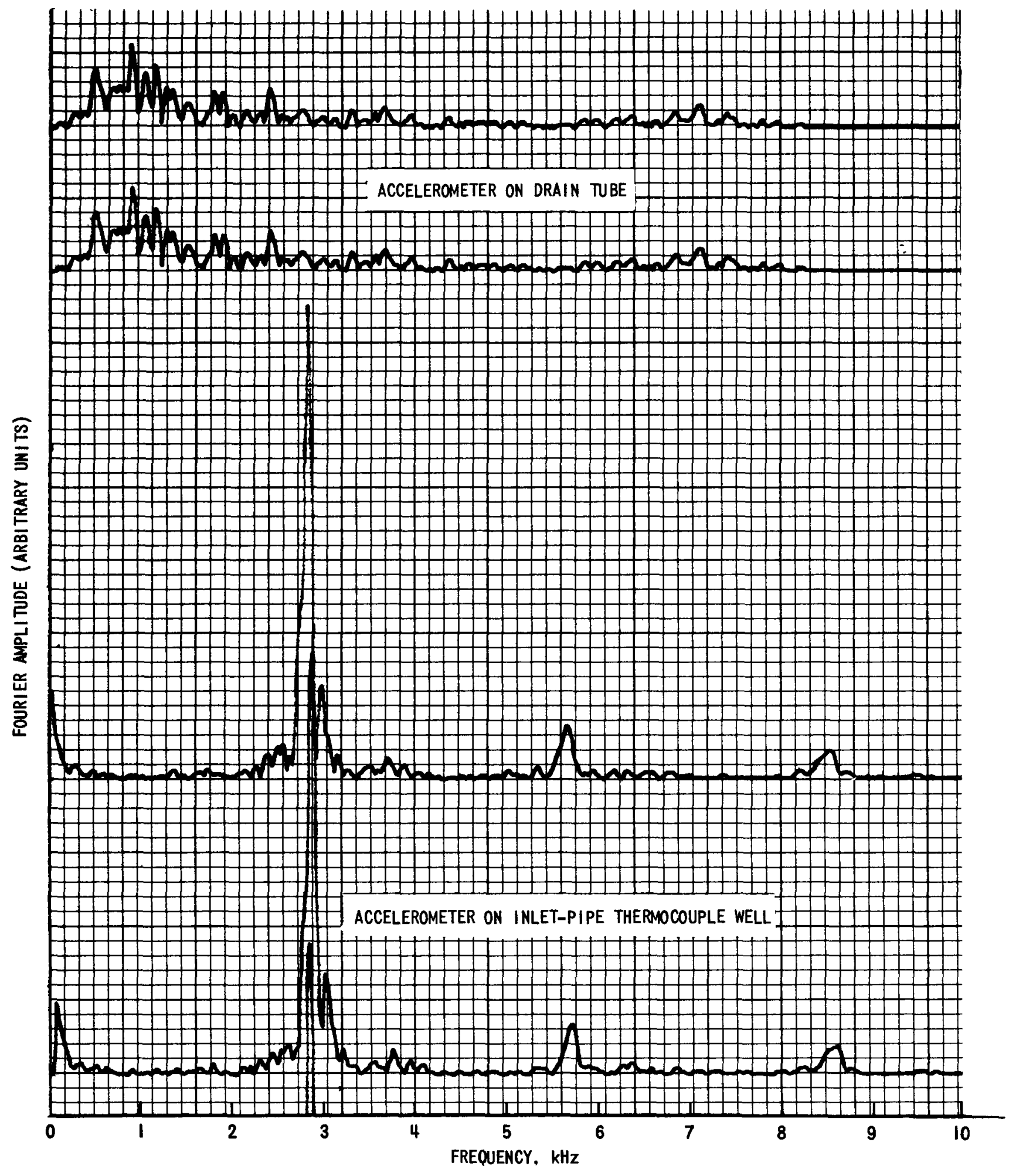

Fig. 11. Transient Capture of Actual IHX Noise at 79\% Secondary Flow When On1y the Accelerometer on the Inlet-pipe Thermocouple Well Was Excited by the Noise 


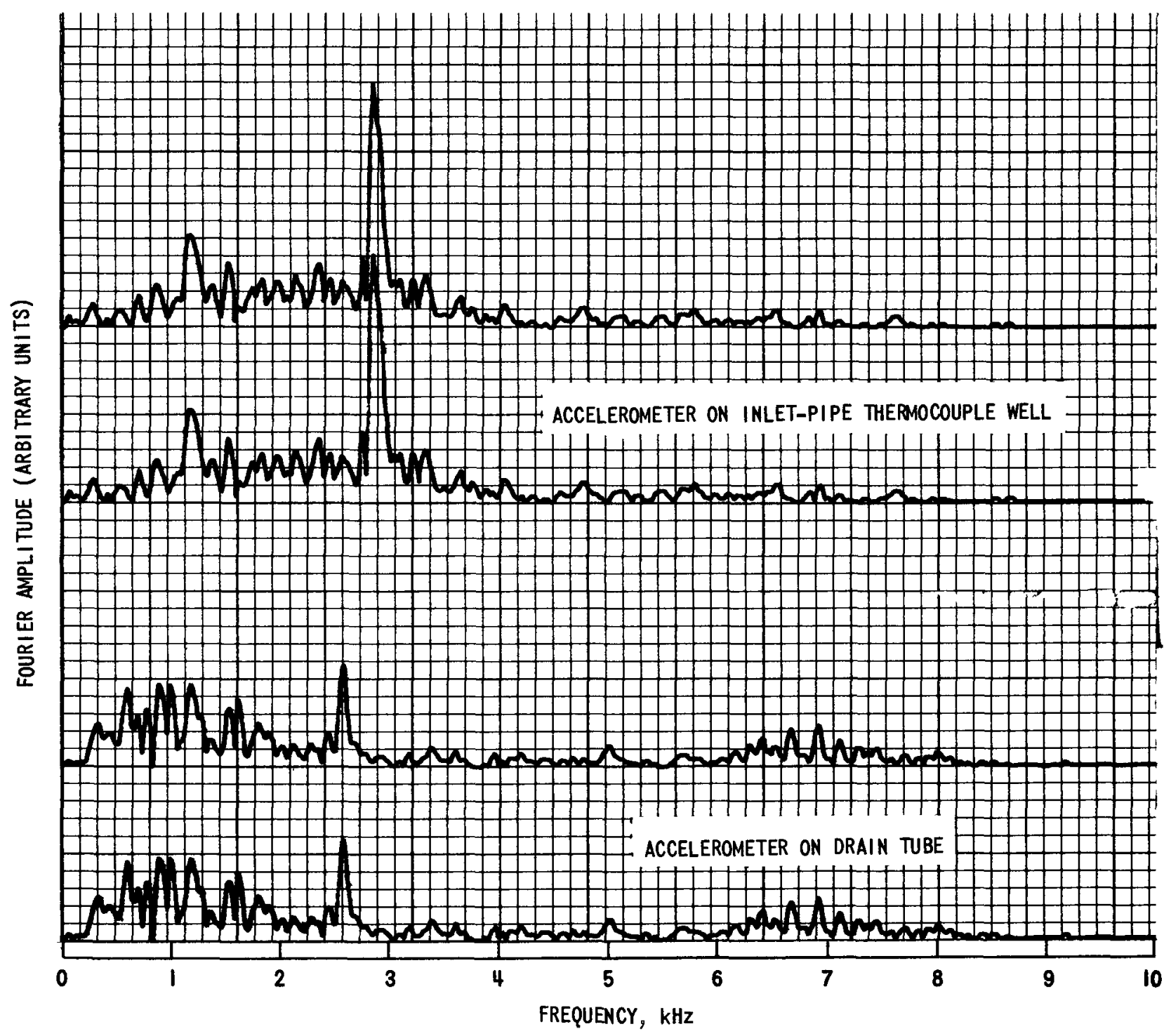

Fig. 12. Transient Capture of Actual IHX Noise at $79 \%$ Secondary Flow when the Accelerometers on the Drain Tube and on the Inletpipe Thermocouple Well Both Were Excited by the Noise 


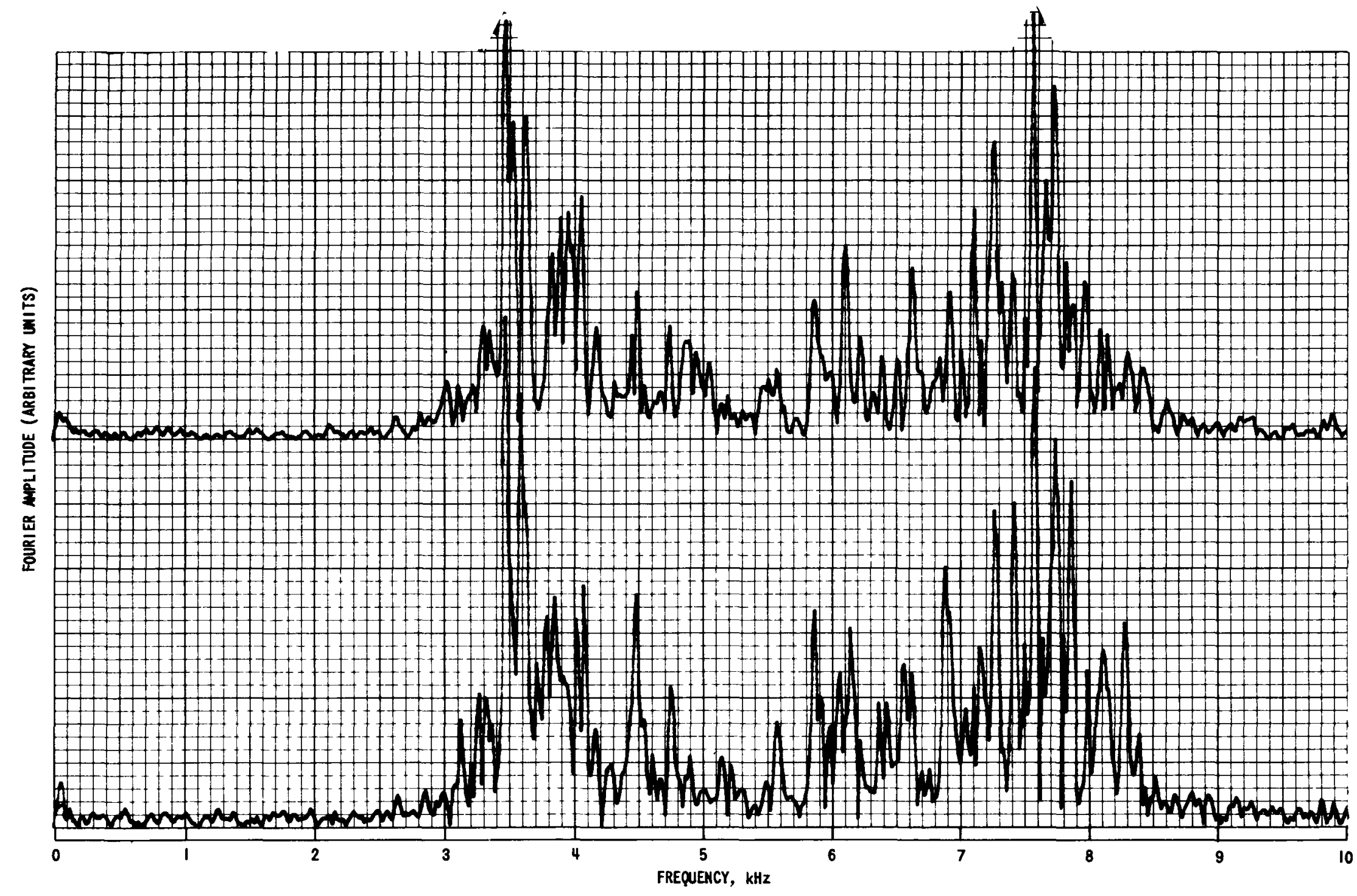

Fig. 13. Noise Produced by Ball-bearing Generator Hitting 18.5 in. above Grid Plate of IHX, as Recorded by Accelerometer on Inlet-pIpe Thermocouple Well 


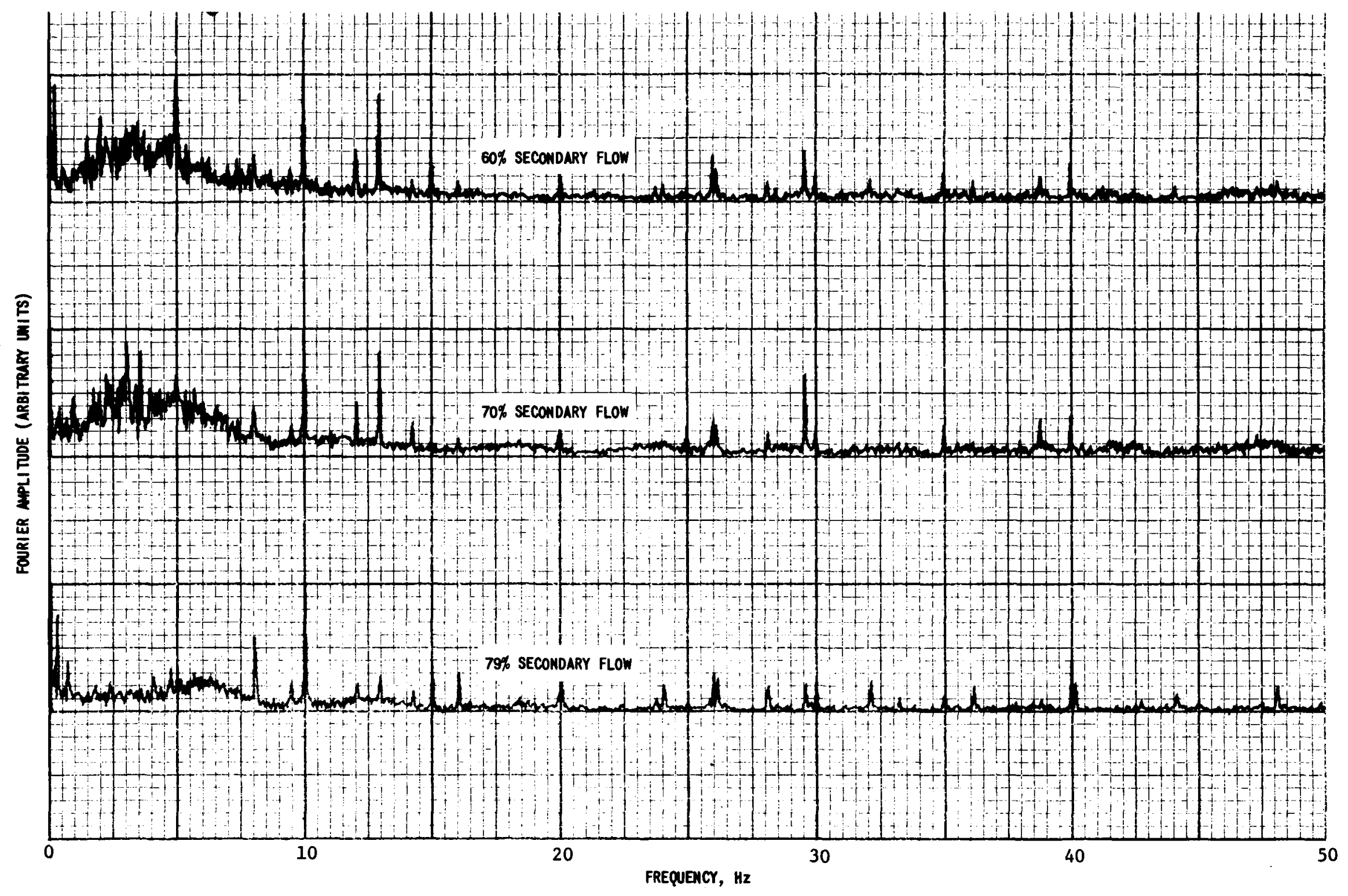

Fig. 14. Verification of Spectrum Analysis of IHX Flow Noise with the Digital Data Acquisition System (compare with Fig. 10) 
APPENDIX A

Disturbance on Primary-sodium Pump No. 1 on September 29,1970

This is a reproduction of a memo reporting the events related to the disturbance. Editing was limited to clarifying a few passages in the text and putting the figures (illustrations) into a form suitable for printing. All figures are grouped together at the end of the appendix. They are not titled, but are explained in the text.

2 October 1970

TO: W. B. Loewenstein Associate Project Director, EBR-II Analysis

FROM: C. C. Price Analysis and Test Section

SUBJECT: Chronological Events of Sept. 29, 1970-Disturbance on Primary Sodium Pump No. 1

The purpose of this memo is to set down in chronological order the events during the power perturbation that occurred in the EBR-II primary sodium pump No. 1 on Sept. 29, 1970.

Time Event

1410* Log entry, "Noticed that No. 1 primary pump $\mathrm{kW}$ increased $\approx 5 \mathrm{~kW}$ with no change in primary flow indication, continuing surveillance." (Figure A-1 shows the power perturbation.)

$\approx 1420$ At this time the power perturbation was noted and the reactor supervisor sent the operator down to examine the pump. The operator reported he could see nothing abnormal but the pump sounded noisier than usual.

$\approx 1430$ Joe Davis came to room 18 and asked if the noise on pump No. 1 could be observed on the spectrum analyzer. We set the equipment up and were able to get our first plots at about 1500 (Fig. A-2).**

* This time entry was dated in the log according to the strip chart ** time scale.

Fourier amplitude on the plots throughout this report are in Grms = gravities in root mean square. 
Time Event

Prior to this we were able to observe the pump noise on the oscilloscope and it appeared to die down significantly as we set up the analyzer. Shown in Fig. A-3 are a series of plots taken in sequence. As can be seen, the plot at 1515 is less noisy than the plot taken at 1500 and the noise seems to continue to die down.

1535 Log entry, "Primary pump No. $1 \mathrm{~kW}$ has been stable since 1410 entry."

2210 Log entry, "Observed several spikes on recorder for primary pump No. 1. Turned on special noise recorder for 5 min."

The 2210 data (Fig. A-4) were plotted on the morning of Sept. 30, 1970, and found to show no significant-difference from the data taken at 1615 (Fig. A-5) the previous day. For comparison, Fig. A-6 shows the noise data during the rise to power for run $46 \mathrm{~A}$.

Conclusions:

1. It appears that the perturbation in pump No. 1 power consumption was real and associated with pump noise.

2. The exact cause of the perturbation is not known at present although one can postulate foreign material entering and clearing the bearings .

3. The pump seems to have returned to nearly the same configuration it had for $62.5 \mathrm{MW}$ at the beginning of run $46 \mathrm{~A}$ (compare Figs. A-5 and A-6). 


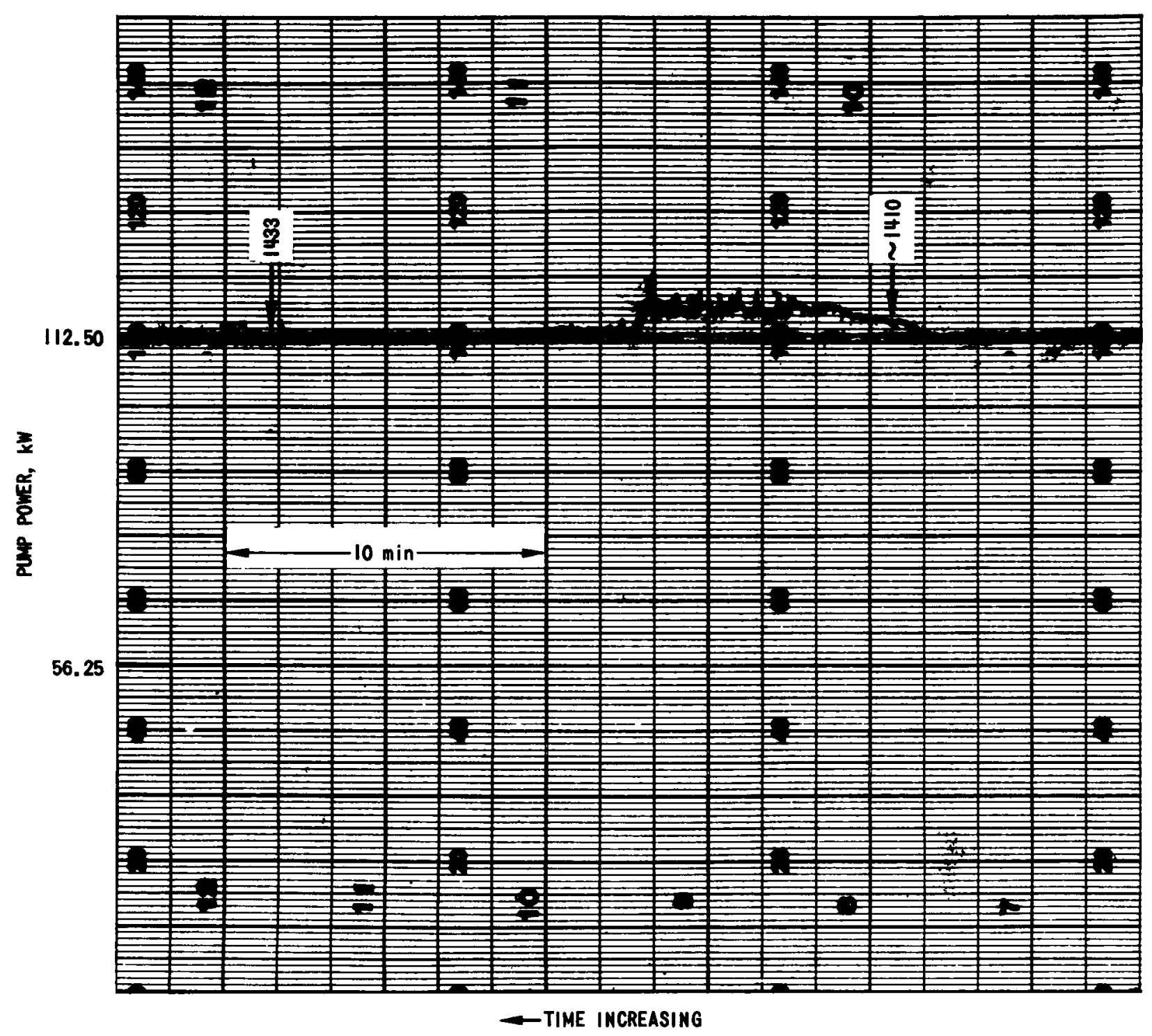

FIG. A-I 


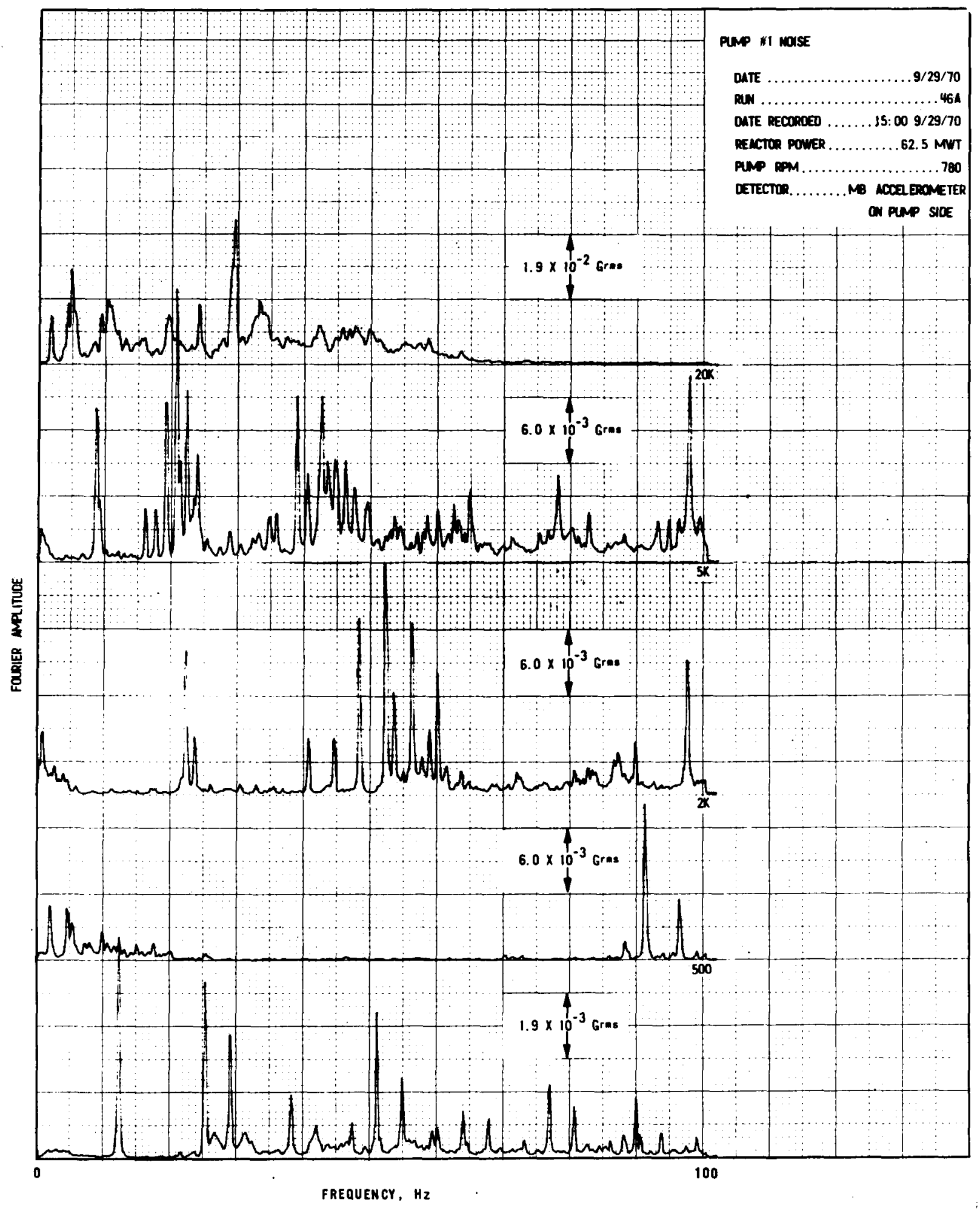

FIG. A-2 


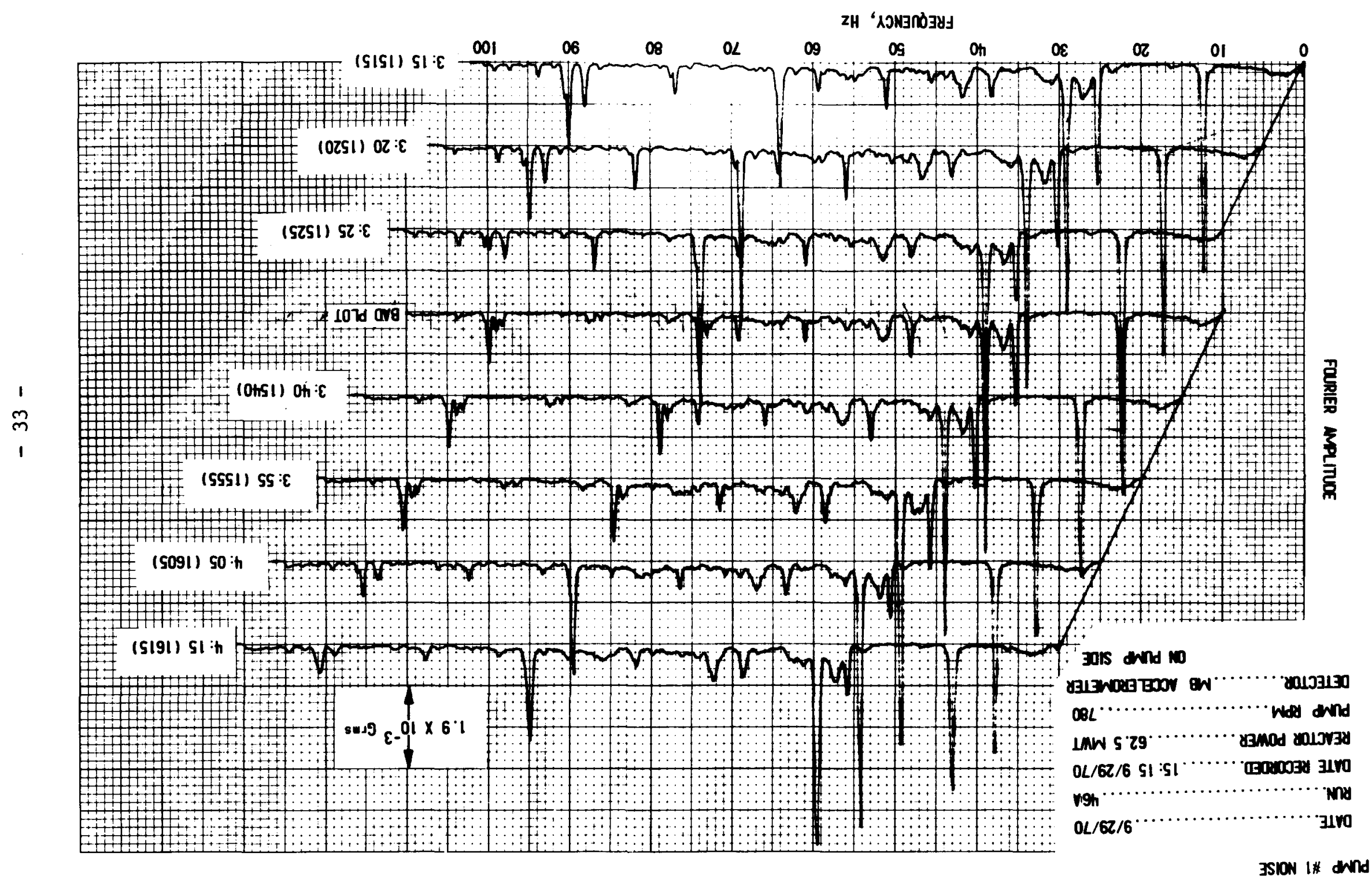




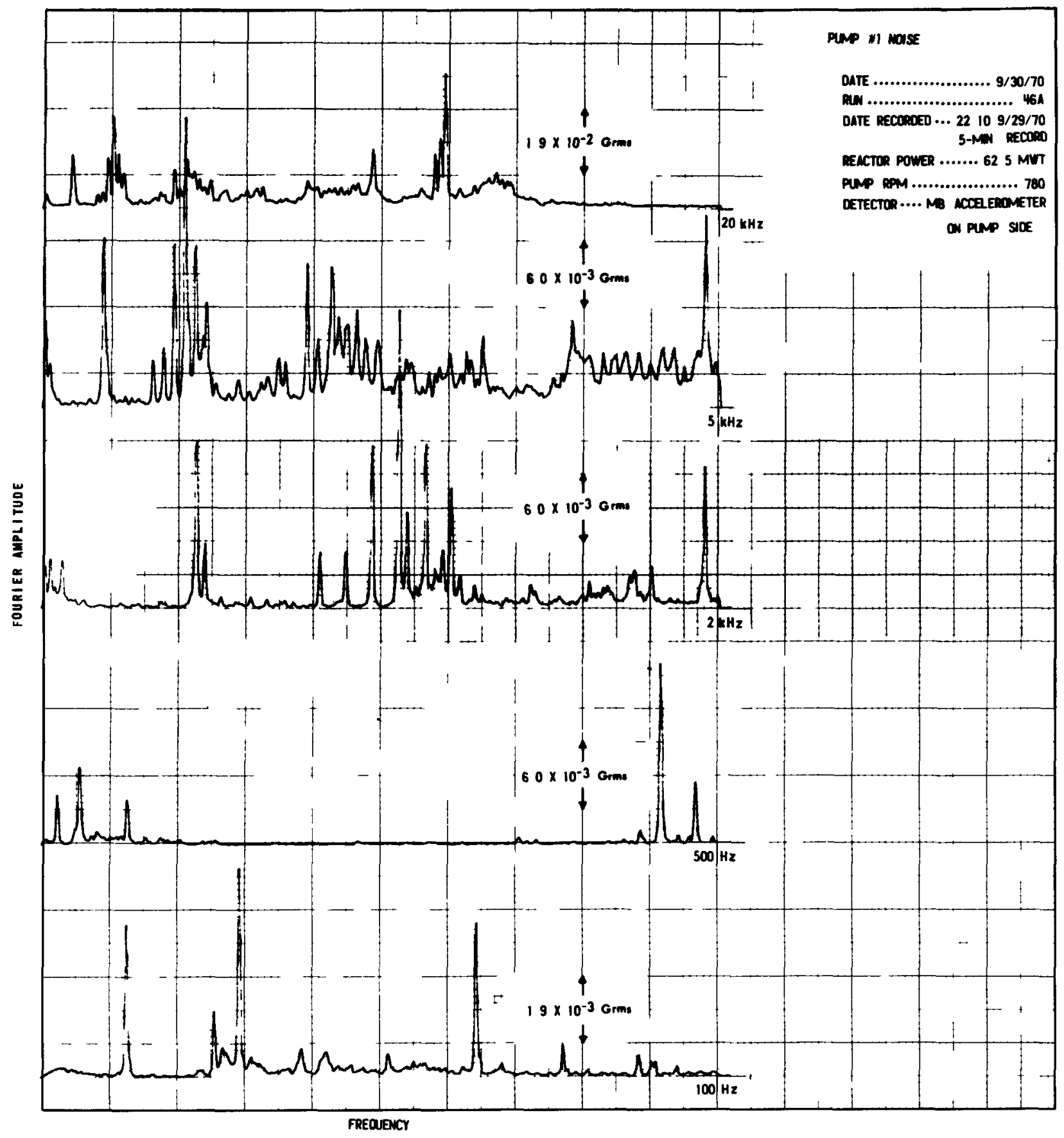

FIG. A-4 


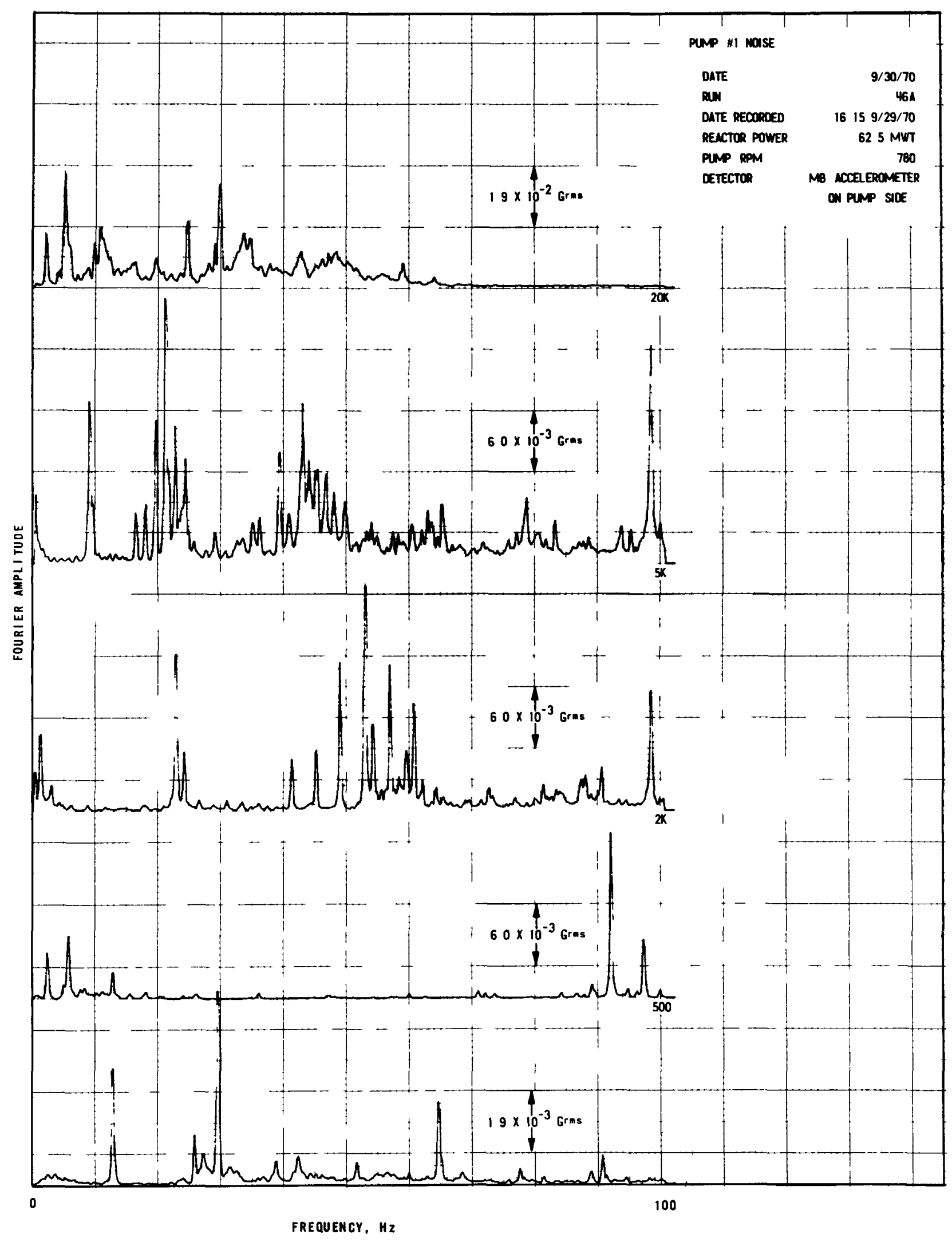

FIG A-5 


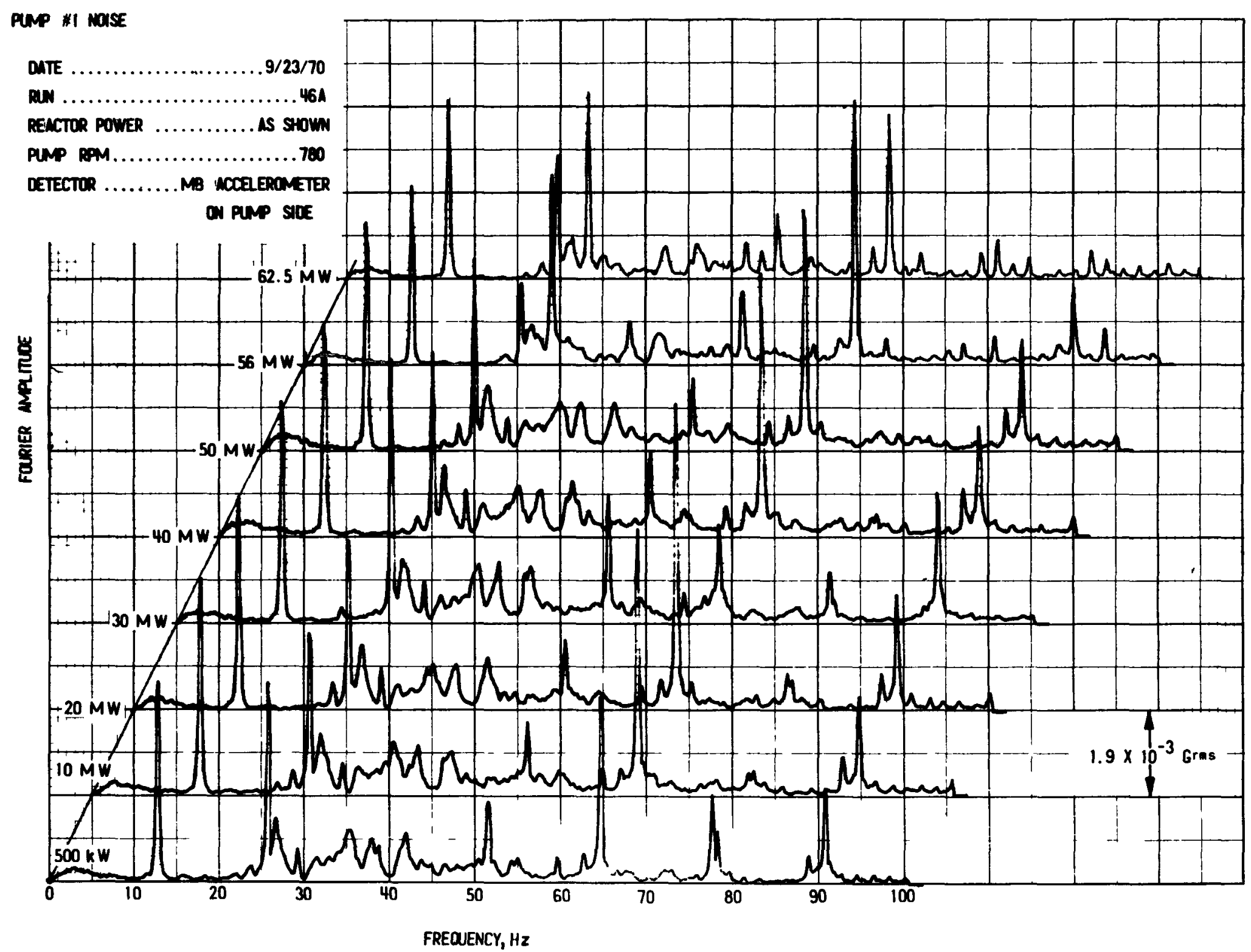

FIG. $A-6$ 
APPENDIX B

Noise Monitoring of the Intermediate Heat Exchanger

This is a reproduction of a memo summarizing noise-signature work done on the intermediate heat exchanger ( IHX) before and after unusual, audible noise was discovered emanating from the region of the IHX on November 14, 1970. Editing was limited to clarifying a few passages in the text and putting the figures (illustrations) into a form suitable for printing.

The original memo contained an error associated with Fig. B-10. This error is corrected at the end of the narrative of the memo as reproduced here, in the section Correction of Error in Original Memo.

All figures are grouped together at the end of the appendix.

30 November 1970

TO: $\quad$ W. B. Loewenstein Associate Project Director, EBR-II Analysis

FROM: $\quad$ J. R. Karvinen

C. C. Price Analysis and Test Section

SUBJECT: Noise Monitoring of the Intermediate Heat Exchanger

The purpose of this report is to record the noise-signature work done on the EBR-II intermediate heat exchanger (IHX) prior to and following the discovery of unusual noises on the assembly on Nov. 14, 1970.

I. Monitoring Prior to Nov. 14, 1970

Prior to the Nov. 14 discovery, the secondary-sodium outlet of the IHX was monitored several times as part of the signature-analysis program. This monitoring was discontinued after a short period of time because the location was near the ion-chamber circuitry that operated the period trips and there was some concern that movement in this area would cause a reactor scram. However, sufficient data were taken to offer reasonable assurance that the noise in the heat exchanger was not present prior to Aug. 21, 1970. 
II. Data Acquisition Program Following the Nov. 14, 1970 Discovery

A. Planned Test Program

This program represents what was planned to be done.

1. Increase secondary flow to that equivalent to $62.5 \mathrm{MWt}$

operation. (A preliminary stop at a lower flow such as at $30 \mathrm{MWt}$ may be used to check out the test components at a lower level.)

2 . Record simultaneously the outputs of one reference accelerometer, one movable accelerometer, and one movable microphone. The latter two will be moved to several (at least three each) different locations on the inlet and on the outlet pipes for the secondary sodium (see Fig. B-1). One (the first) location of the movable accelerometer will be on the drain tube in the inlet pipe to the heat exchanger.

3. Record, again simultaneously with the reference accelerometer, the primary pumps. Vary the primary pump flow to four levels during this recording.

4. Reduce the secondary flow to the $50,40,30,20,10$, and 0 MWt levels (with primary pumps at $100 \%$ flow).

5. For step 4 repeat each of the test-point recordings of the 62.5 MWt run.

\section{B. Actual Test Program}

The test program, except for a few minor changes, was carried out as outlined in Section $A$ :

1. A preliminary stop was made at $30 \mathrm{MWt}$ equivalent flow to test the instrumentation and establish a reference.

2. The reference accelerometer (Gulton model $A Q B-4971$, serial number 1073) was attached to a bolt screwed into a thermocouple well on the top of the secondary inlet pipe (position a in Fig. B-1). The location was about $2 \mathrm{ft}$ along the length of the pipe from the elbow. The movable (roving) accelerometer (MB Electronics model 354) was located at the following points:

a. On the drain tube (position $b$, directions $x, y$, and $z$, in Fig. B-1).

b. On a thermocouple well at elbow of the outlet pipe (position c in Fig. B-1).

c. On a thermocouple well about $10 \mathrm{ft}$ back from the elbow on the outlet pipe (position d in Fig. B-1). 
d. On a thermocouple well about $8 \mathrm{ft}$ from the elbow on the inlet pipe (position e in Fig. B-1).

It was found best to leave the microphone at the drain tube (b in Fig. B-1) throughout the actual test.

3. Part three of the test was done while maintaining the secondary flow at 30 MWt equivalent flow (79\%).

4. Part four of the test was carried out as prescribed; however, the primary pumps were only operated at $97 \%$.

5. Part five was eliminated in order to limit possible damage to or by the noise source.

III. Data Reduction

The reduction of data included the following:

A. Frequency-spectrum analysis,

B. Cross-correlation of known signal source and of signals received from IHX at two different locations,

C. Slowdown of the tape recorder, and strip-chart recording of the resulting slower frequencies.

IV. Results

A. Frequency-spectrum-analysis Results

Because of the various resonances and transmission paths present in the system, the selecting of single frequencies provides 1ittle useful logic. However, the amplitude envelopes showed the noise to be dependent on secondary flow (see Figs. $\mathrm{B}-2$ and $\mathrm{B}-3$ ), independent of primary flow (see Fig. B-4), and conversely that primary flow also was independent of the noise.*

Some distinctive frequency information (Figs. B-5 and B-6) indicates a fundamental frequency of the highest noise recorded is often 4 to $6 \mathrm{~Hz}$, but this is not a rhythmic occurrence, i.e., it does not occur again at the same interval of time but at random intervals. Also observed

* This memo discusses primarily the data from the reference accelerometer ( $a$ in Fig. A-1) and from the roving accelerometer at position $b$, direction $\mathrm{x}$, on the drain tube and position $c$ on the outlet-pipe elbow. Time was not available to make thorough measurements at all points. The data for position $b$, direction $x$, and for position $c$ were the most comprehensive obtained. 
in these plots are several higher frequencies that appear to be dependent on secondary flow. However, these frequencies are not readily apparent in the strip-chart data, which were dominated by the lower frequency of the random banging patterns.

The relative amplitude of the noise was at least three times stronger on the drain-tube accelerometer at $50 \mathrm{MW}$ than it was at $30 \mathrm{MW}$. The noise level on the inlet pipe was stronger by an order of magnitude than that on the outlet pipe.

\section{B. Cross-correlation Results}

Results from cross-correlation of the various accelerometer signals were inconclusive. This situation was primarily due to the lack of experience with the correlator unit (a unit borrowed from ANL-Illinois) and the complexities of the geometry involved. Prior cross-correlation data (signatures) of the "intact" heat exchanger would have been extremely valuable in tracing the source of the present noise.

\section{Tape-slowdown Results}

The "slowdown" recordings (Figs. B-7 and B-8) gave the following information:

1. The accelerometer on the drain tube occasionally was not excited by the noise source as recorded on the reference accelerometer.

2. The repetition rate of the loudest noise was about $6 \mathrm{~Hz}$, and usually occurred 4 times and then disappeared for a noticeable period of time.

3. At times the noise would be continuous, i.e., before it died out to normal background level, it would "bang" again.

V. Analysis of the Reduced Data

The following table lists the logic gleaned from the noise data and the chronological events relative to the problem.

Deviation

Should be: quiet flow in secondary. Actually is: flow-dependent intermittent noise. 


\begin{tabular}{|c|c|c|c|c|}
\hline & Is & Is Not & Distinction & Changes \\
\hline What: & Intermittent noise & Continuous & $\begin{array}{l}\text { Randomly occurring spec- } \\
\text { trum. }\end{array}$ & \\
\hline Where: & In IHX & $\begin{array}{l}\text { In primary } \\
\text { side }\end{array}$ & $\begin{array}{l}\text { Stronger on inlet pipe } \\
\text { than outlet and strongest } \\
\text { on drain tube. Drain } \\
\text { tube proven intact by } \\
\text { bubble test. }\end{array}$ & \\
\hline When: & Nov. 14,1970 & $\begin{array}{l}\text { Before } \\
\text { Aug. } 21 \\
1970\end{array}$ & $\begin{array}{l}50 \mathrm{MW} \text { operation before } \\
\text { and } 62.5 \mathrm{MW} \text { operation } \\
\text { during initiation. }\end{array}$ & $\begin{array}{l}62.5-M W \\
\text { tempera- } \\
\text { ture, flow, } \\
\text { pressure }\end{array}$ \\
\hline Extent: & $\begin{array}{l}\text { Secondary-flow- } \\
\text { dependent and three } \\
\text { times as strong at } \\
50 \mathrm{MW} \text { as at } 30 \mathrm{MW} \text {. } \\
\text { Stronger on inlet } \\
\text { pipe than outlet } \\
\text { pipe; strongest } \\
\text { on drain tube. }\end{array}$ & $\begin{array}{l}\text { Influencing } \\
\text { the primary } \\
\text { flow }\end{array}$ & $\begin{array}{l}\text { Confined to secondary } \\
\text { side of IHX and } \\
\text { predominant on inlet } \\
\text { side and where drain } \\
\text { tube is the best } \\
\text { waveguide, i.e., the } \\
\text { top of the grid at the } \\
\text { bottom of the IHX. }\end{array}$ & \\
\hline
\end{tabular}

VI. Development of Probable Causes

A. The drain tube is vibrating: The bubble test and the fact that the noise occasionally (although not often) is not present on the accelerometer monitoring the tube suggests this tube is not the probable cause.

B. A loose baffle: The odds that a baffle was torn completely loose by flowing sodium is improbable. If, then, it is torn loose at one end, it should provide a relatively rhythmic pattern of frequencies each time and repeat. The data indicate that the noise is sporadic in frequency or occurrence. Also the drain tube should pick it up each time in the same manner or repeat times when no noise is seen in a uniform manner.

C. A foreign object in the IHX: The fact that the noise spectrum is randomly occurring suggests a loose object. Increased flow and pressure indicate that something lodged in the secondary loop could become lodged by this increase. The entire system up to the grid plate of the IHX could pass an object of relatively good size. The bottom of the IHX is the lowest point of the system, a natural place for something loose to ultimately locate itself. The drain tube is the best waveguide for noise from the bottom of the IHX because it is firmly attached there and, except for two 
points where it is clamped along the inlet pipe, will transmit considerable energy to the top of the tube. The inlet pipe displaying a higher level of noise than the outlet pipe indicates that the noise source may probably be banging this pipe directly. The amplitude of the noise generator dictates that it is a piece of considerable size and consequently is probably loosely lodged in the grid at the bottom of the pipe (a 4-in.-radius sector of an octagonally dissected circle). The fact that the drain tube does occasionally miss the noise suggests again that the piece is indeed loose and can bang the inlet pipe or the drain tube at a null point of noise. The relative infrequency of this occurrence augments this observation.

VII. Additional Qualitative Information

Figure B-9 shows the data taken November 14. Figure B-10 shows the data taken on the outlet-pipe elbow prior to and on November 14, 1970 . Also shown in this figure is the noise recorded on the inlet pipe with the reference accelerometer on Nov. 14.

\section{Correction of Error in Original Memo}

The amplitude of the IHX noise on August 21, 1970, was shown incorrectly on Fig. B-10 of the original memo. The Fig. B-10 of this appendix has been corrected to show the correct value, $0.03 \mathrm{Grms}$, as taken from the instrument settings.

Figure B-11 (which was not part of the original memo) was prepared to show that if the unusual noise had been present on August 21, 1970, it would have been observable amid the $60 \mathrm{~Hz}$ and its harmonics. Note (upper trace) that the captured spectra of a single noise burst at $60 \%$ secondary flow (equivalent to 40-MW operation) on November 17, 1970, has four times the peak amplitude of the averaged noise (middle trace) observed at $70 \%$ flow (50-MW operation) on August 21. Note further (lower trace) that averaging the random bursts of November 17 over a period of time gives a Fourier amplitude of only a tenth of the single burst. This is because very low signal amplitude is averaged over the time between bursts, which results in a smaller mean spectrum. 


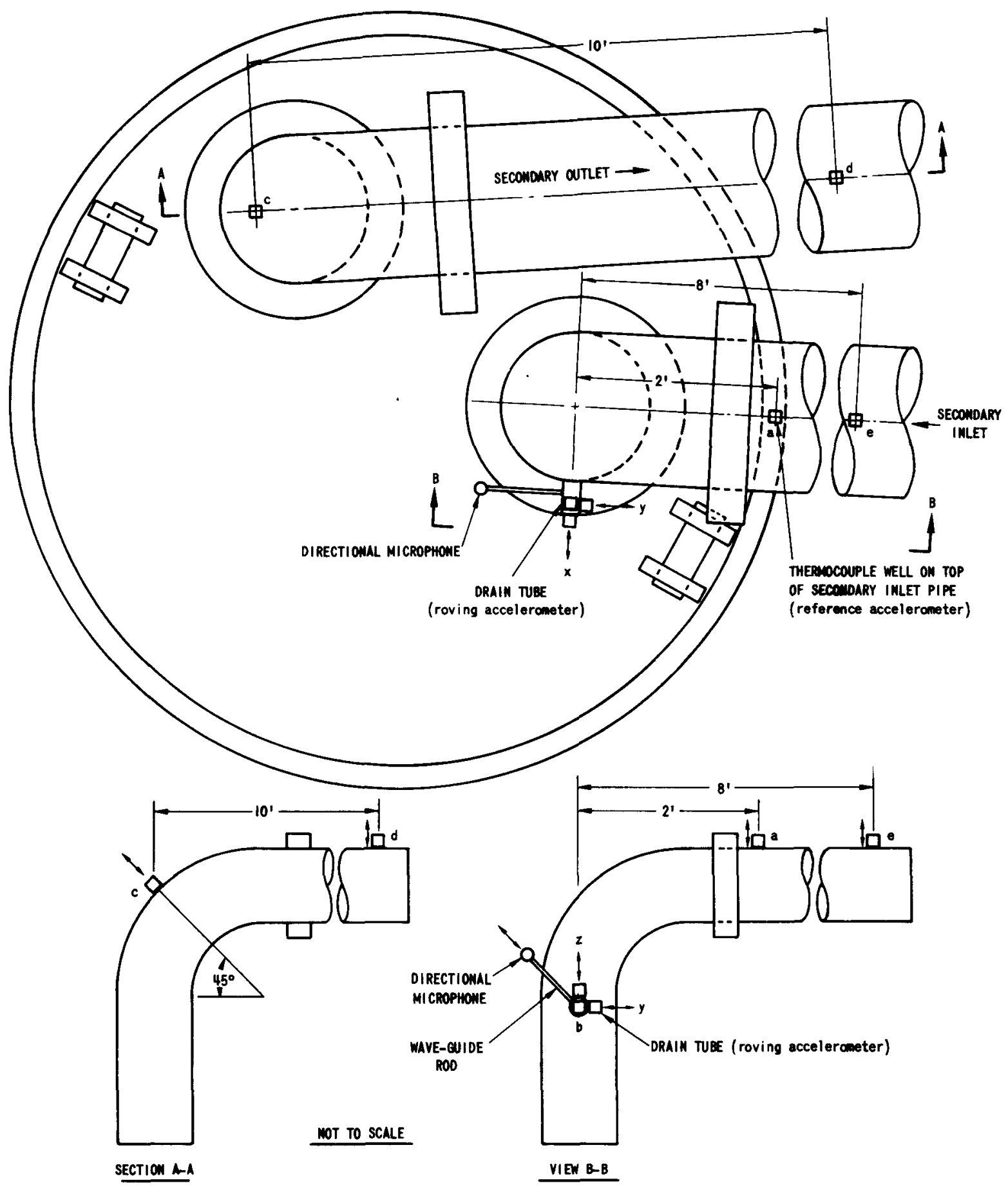

Fig. B-1. Locations of Accelerometers and Microphone for Monitoring IHX Noise in November 1970 


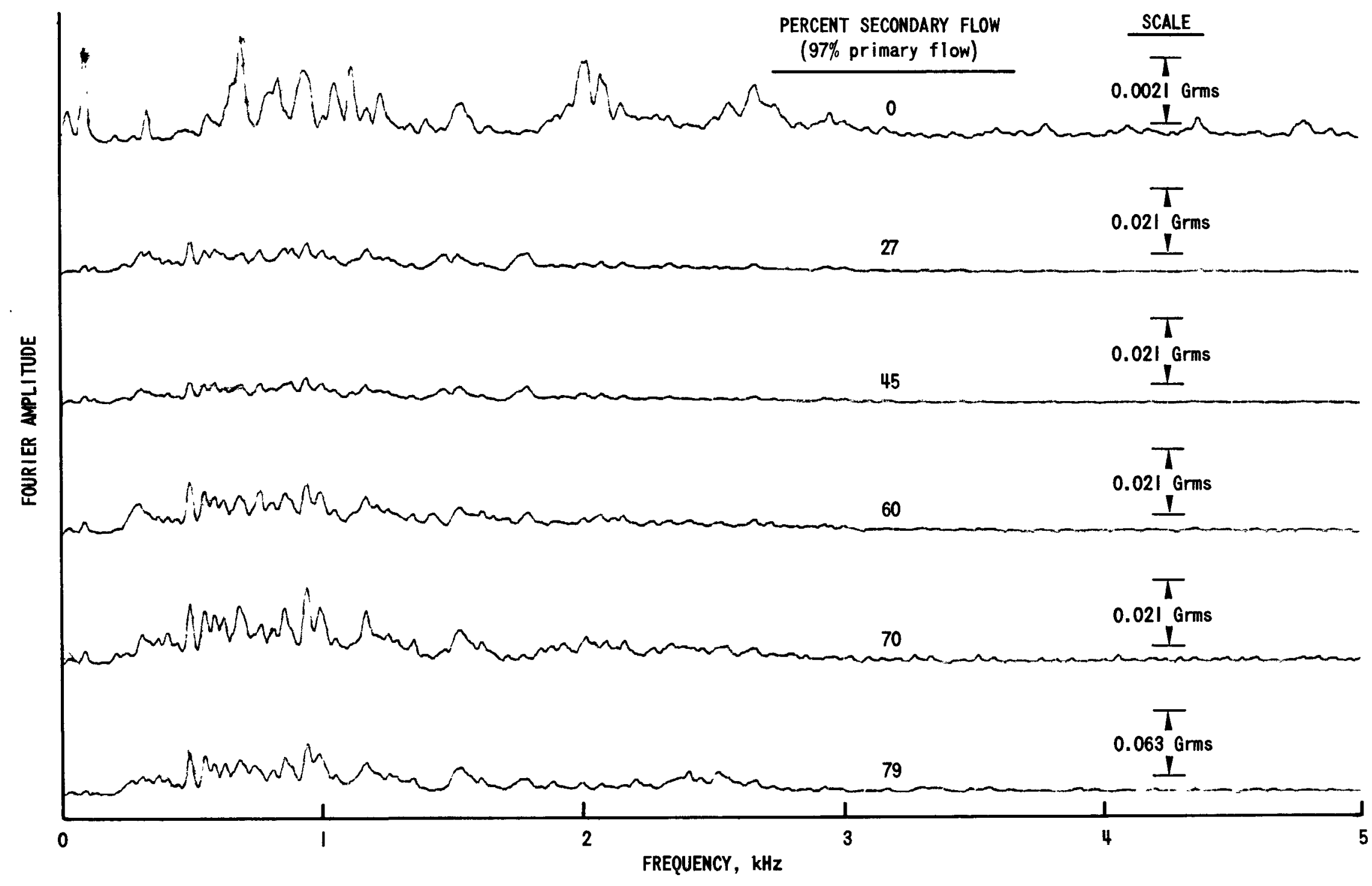

Fig. B-2. Data from Roving Accelerometer (position b, direction x, Fig. B-1) on IHX Drain Tube at Constant Primary Flow and Various Secondary Flows 


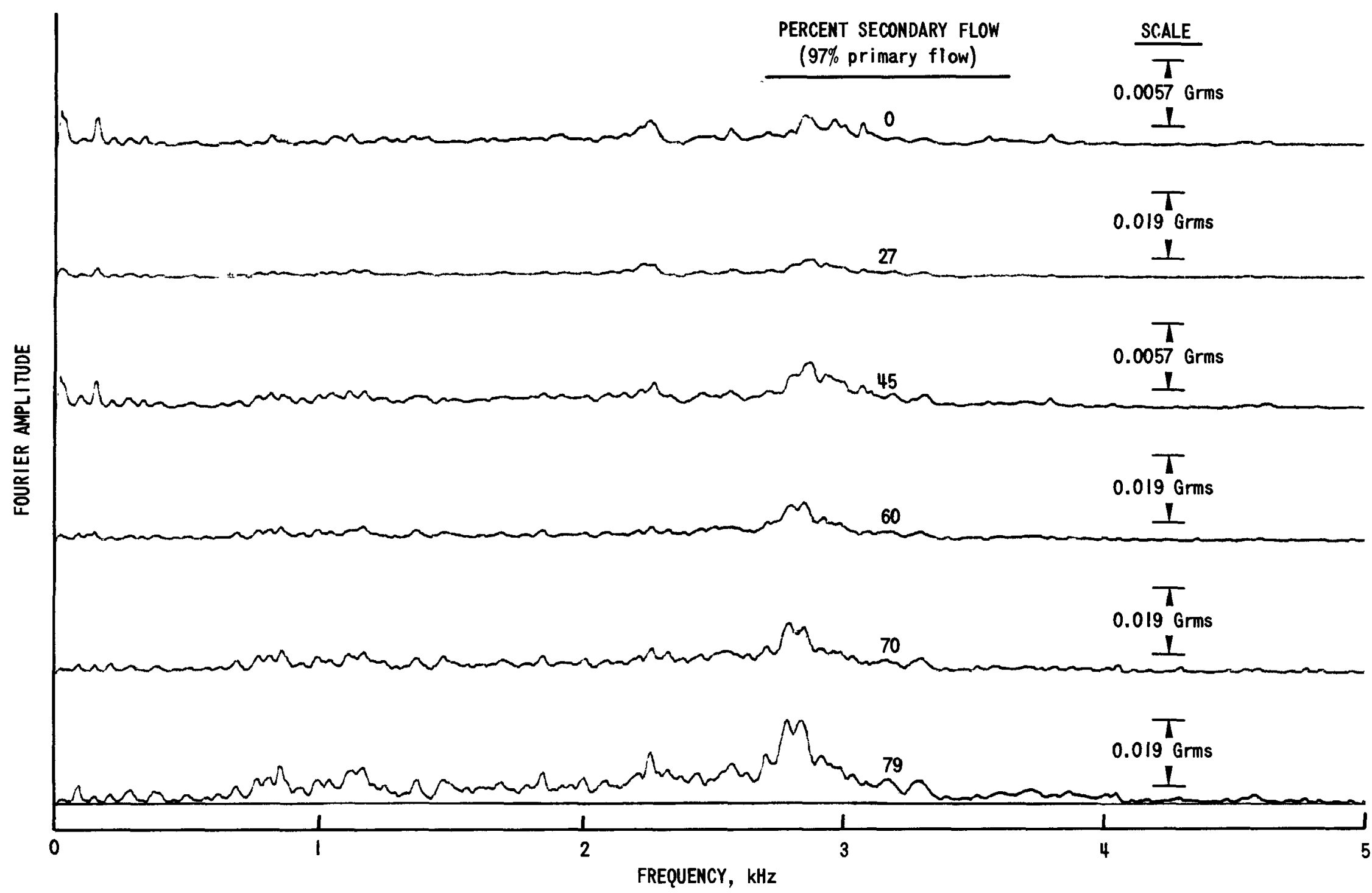

Fig. B-3. Data from Reference Accelerometer (position a, Fig. B-1) at Constant Primary Flow and Various Secondary Flows 


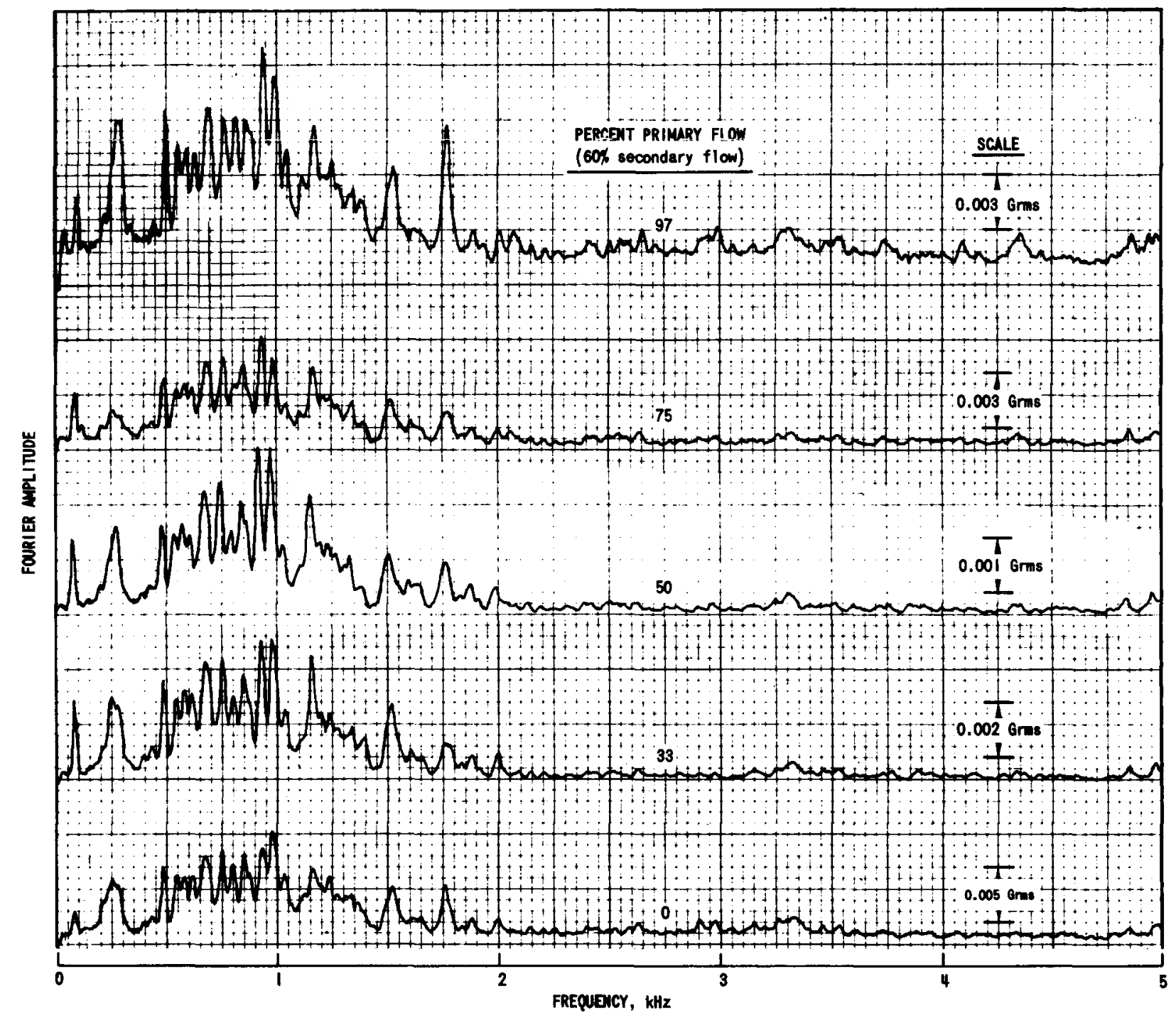

Fig. B-4. Data from Roving Accelerometer (position b, direction x, Fig. B-1) at Constant Secondary Flow and Various Primary Flows 


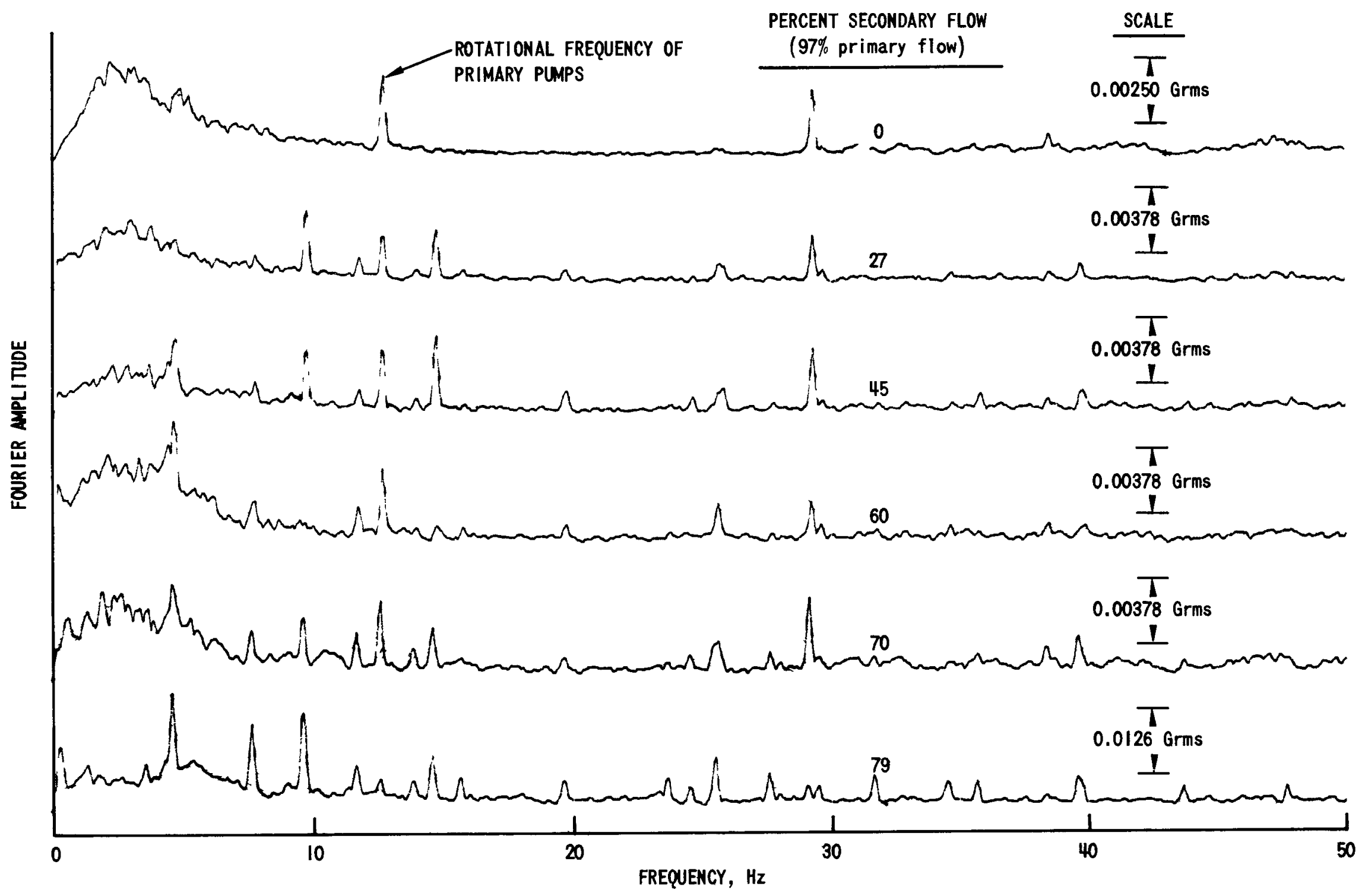

Fig. B-5. Low-frequency Spectra from Accelerometer on Drain Tube (position b, Fig. B-1) 


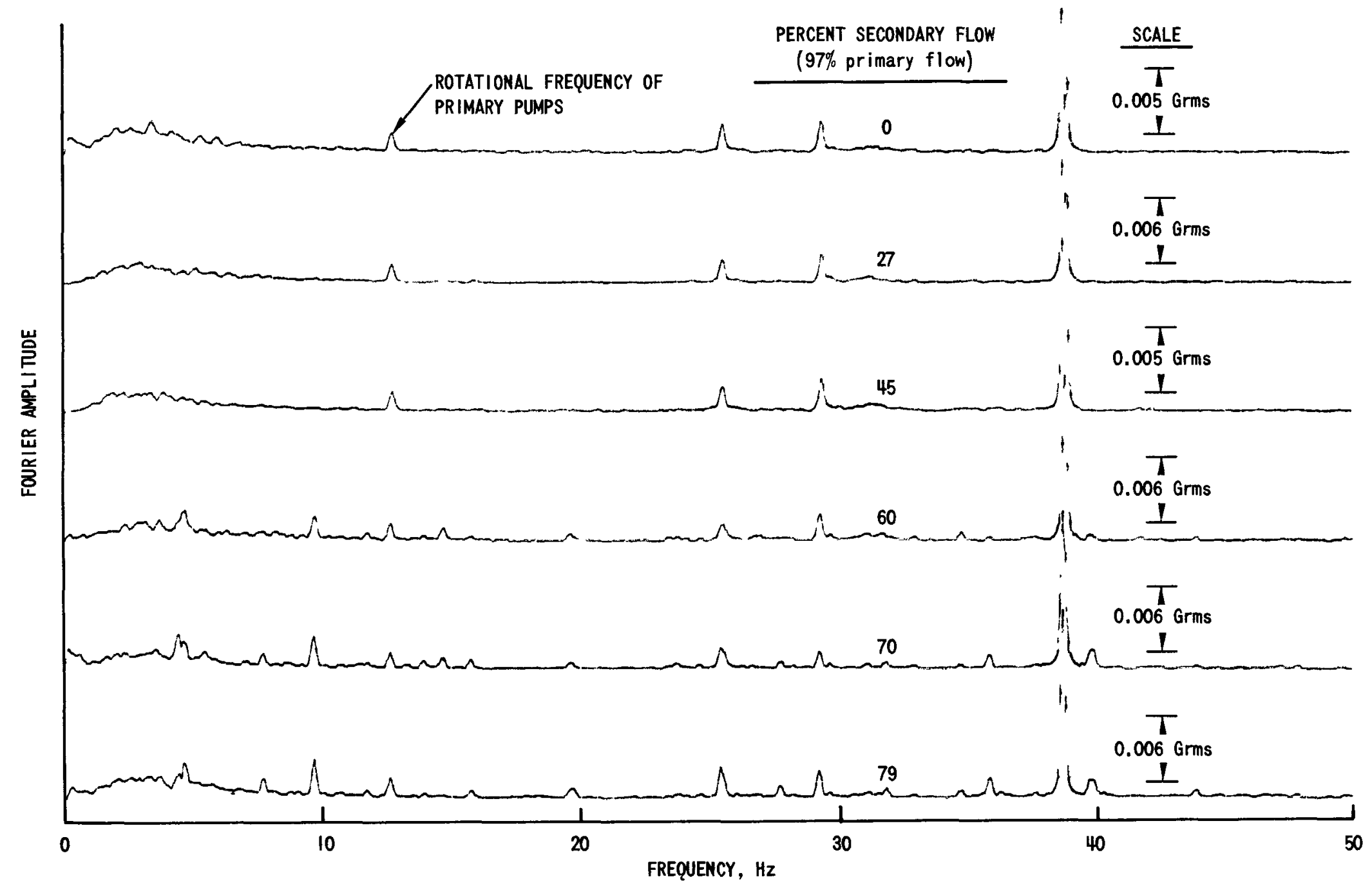

Fig. B-6. Low-frequency Spectra from Accelerometer on IHX Secondary-sodium Inlet Pipe (position a, Fig. B-1) 


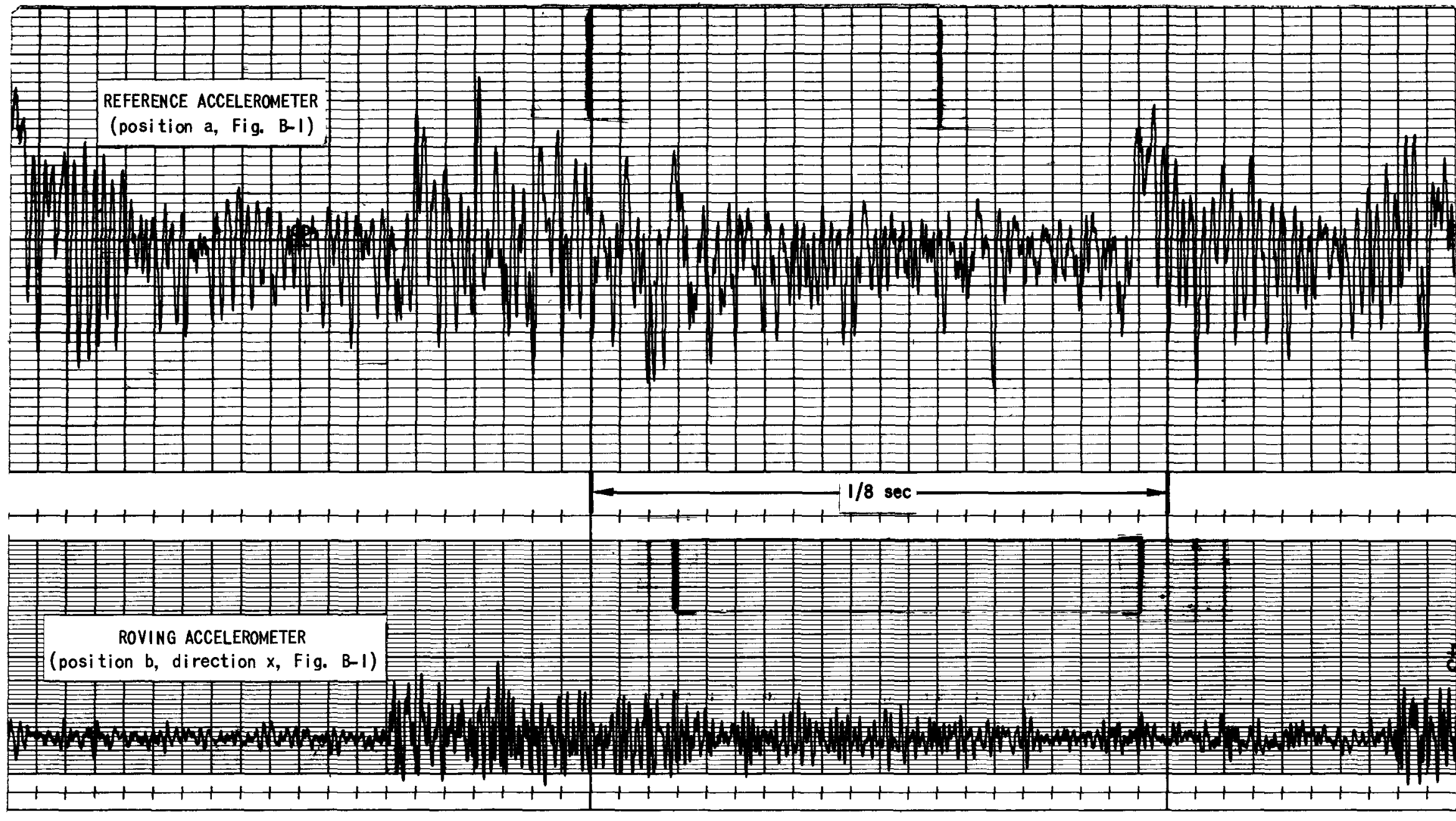

TIME INCREASING $\rightarrow$

Fig. B-7. Noise Registered by Reference Accelerometer, but Not by Roving Accelerometer on Drain Tube 


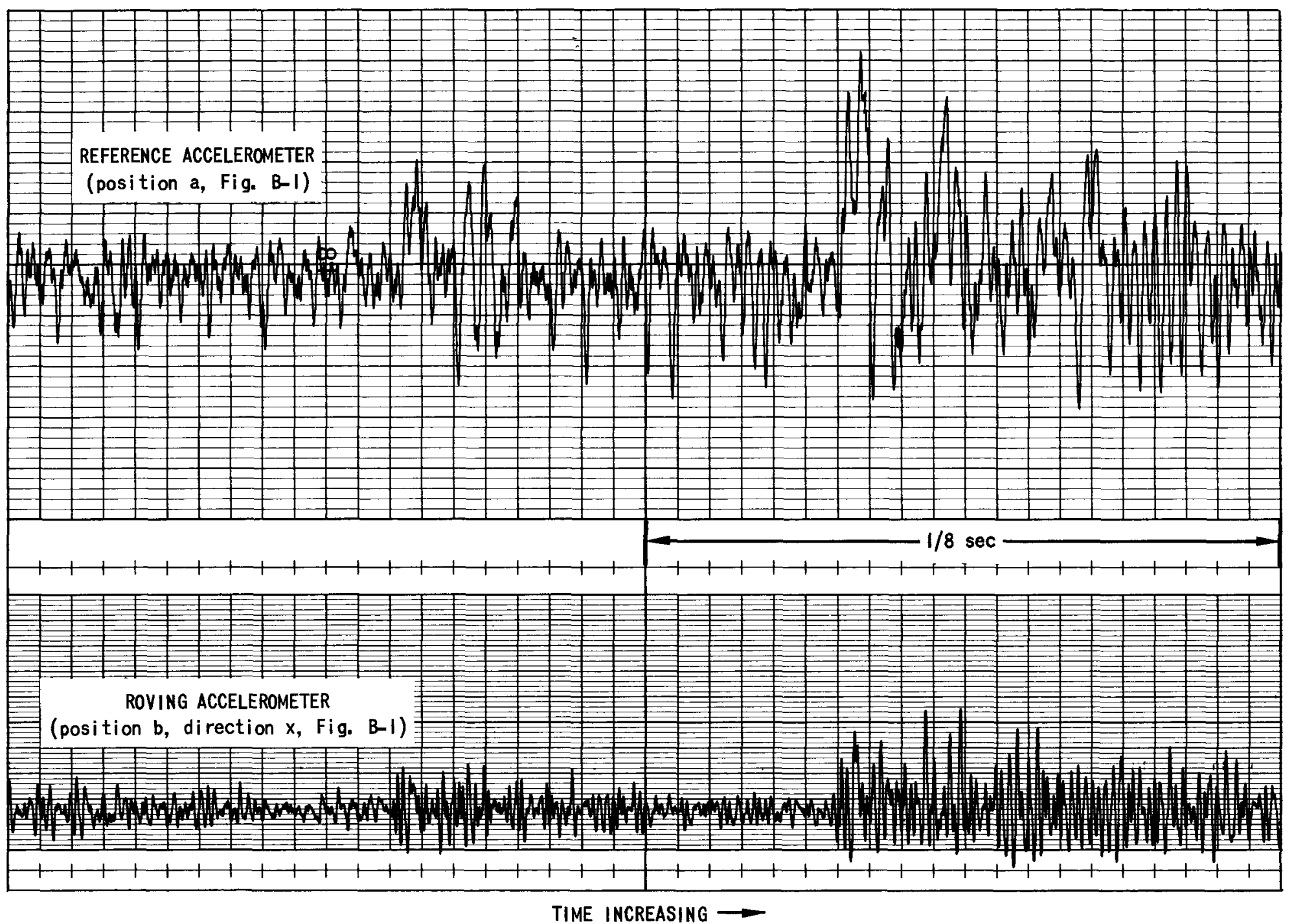

Fig. B-8. Noise Registered Both by Reference Accelerometer and by Roving Accelerometer on Drain Tube 


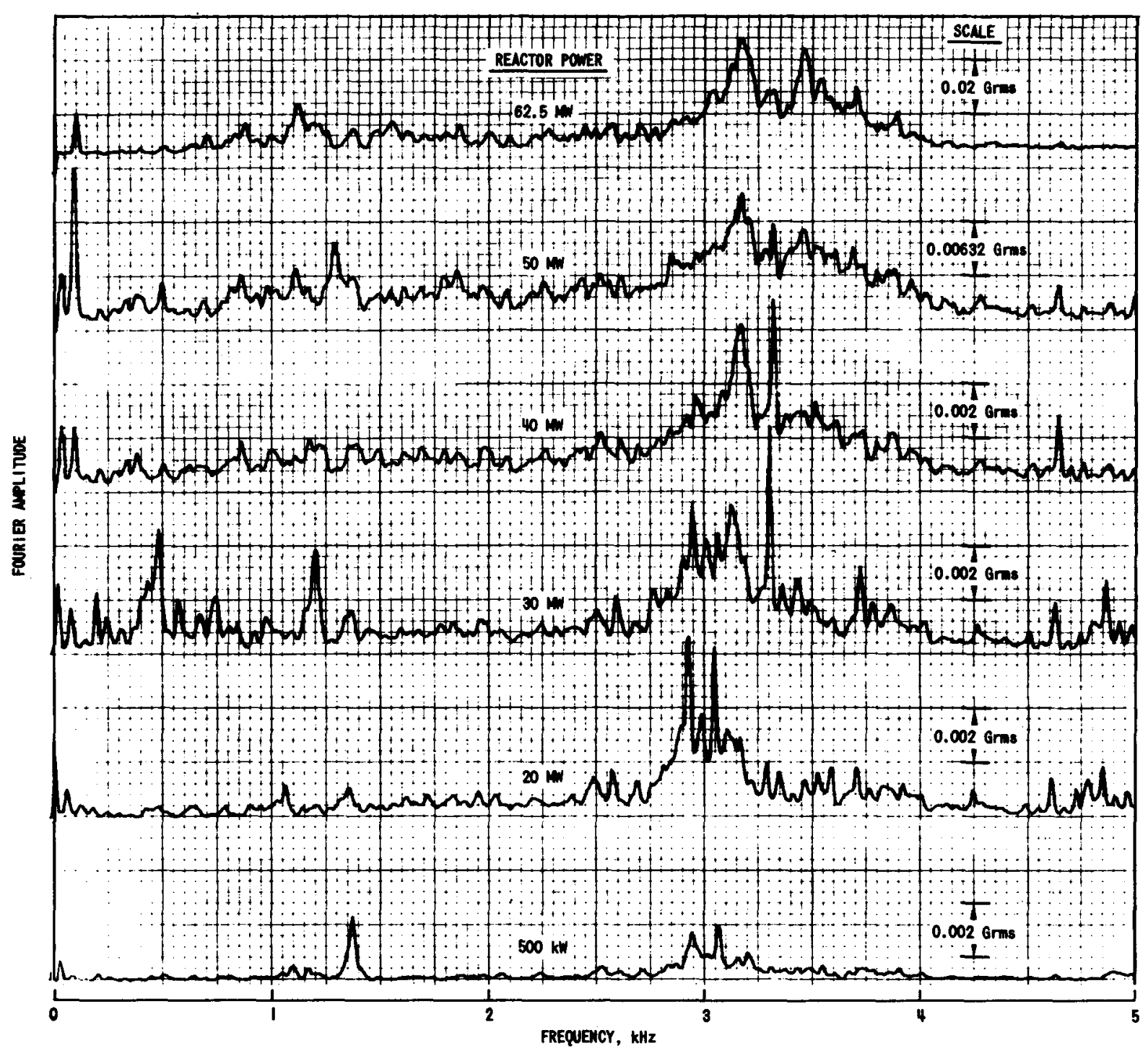

Fig. B-9. Noise Spectra during Shutdown of Reactor on November 14, 1970 (position a, Fig. B-1) 


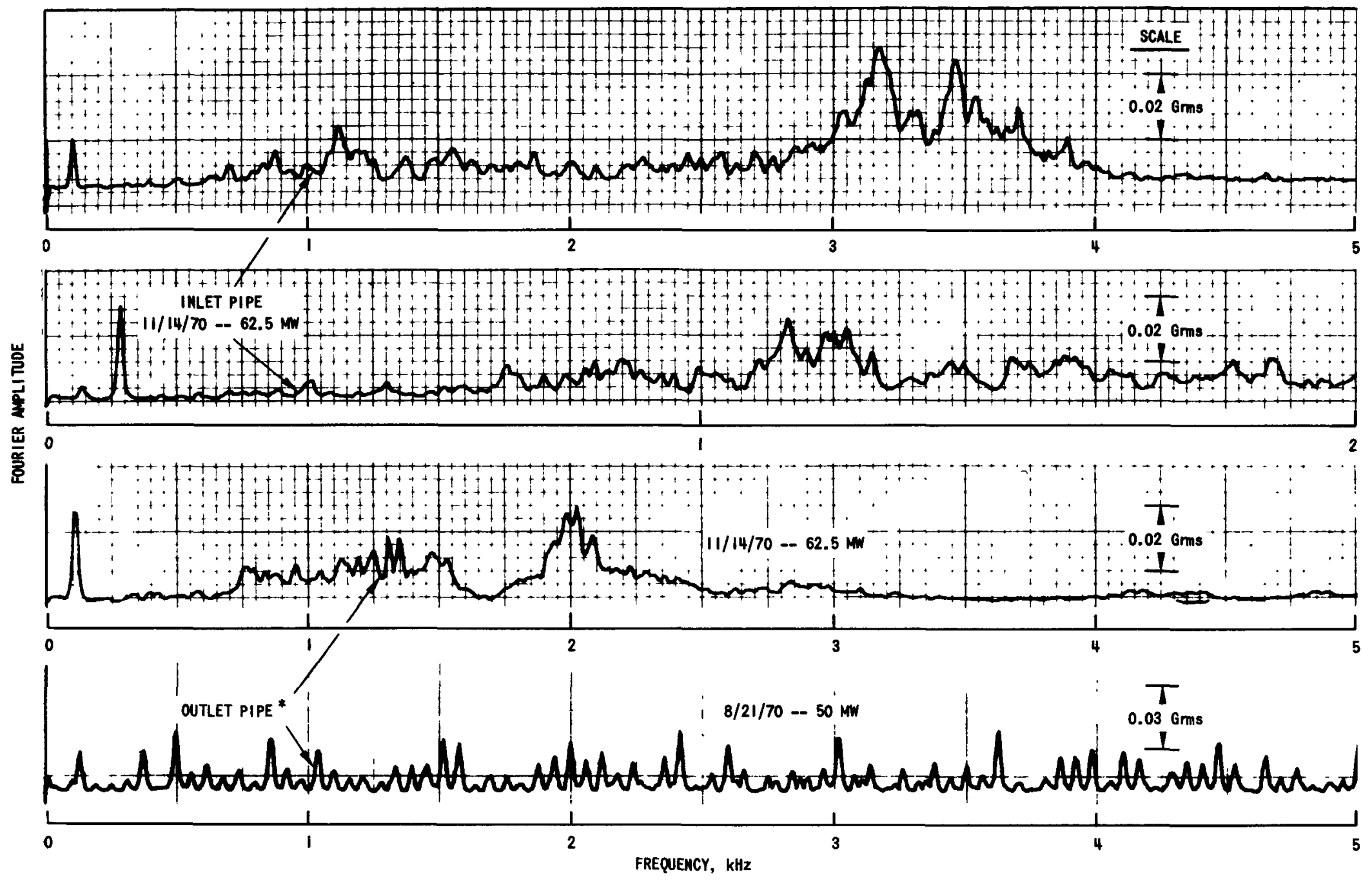

* See supplementary Fig. B-1I and discussion at end of narrative of appendix.

Fig. B-10. Noise on IHX Inlet and Outlet Pipes on November 14, 1970, and on Outlet Pipe on August 21, 1970 


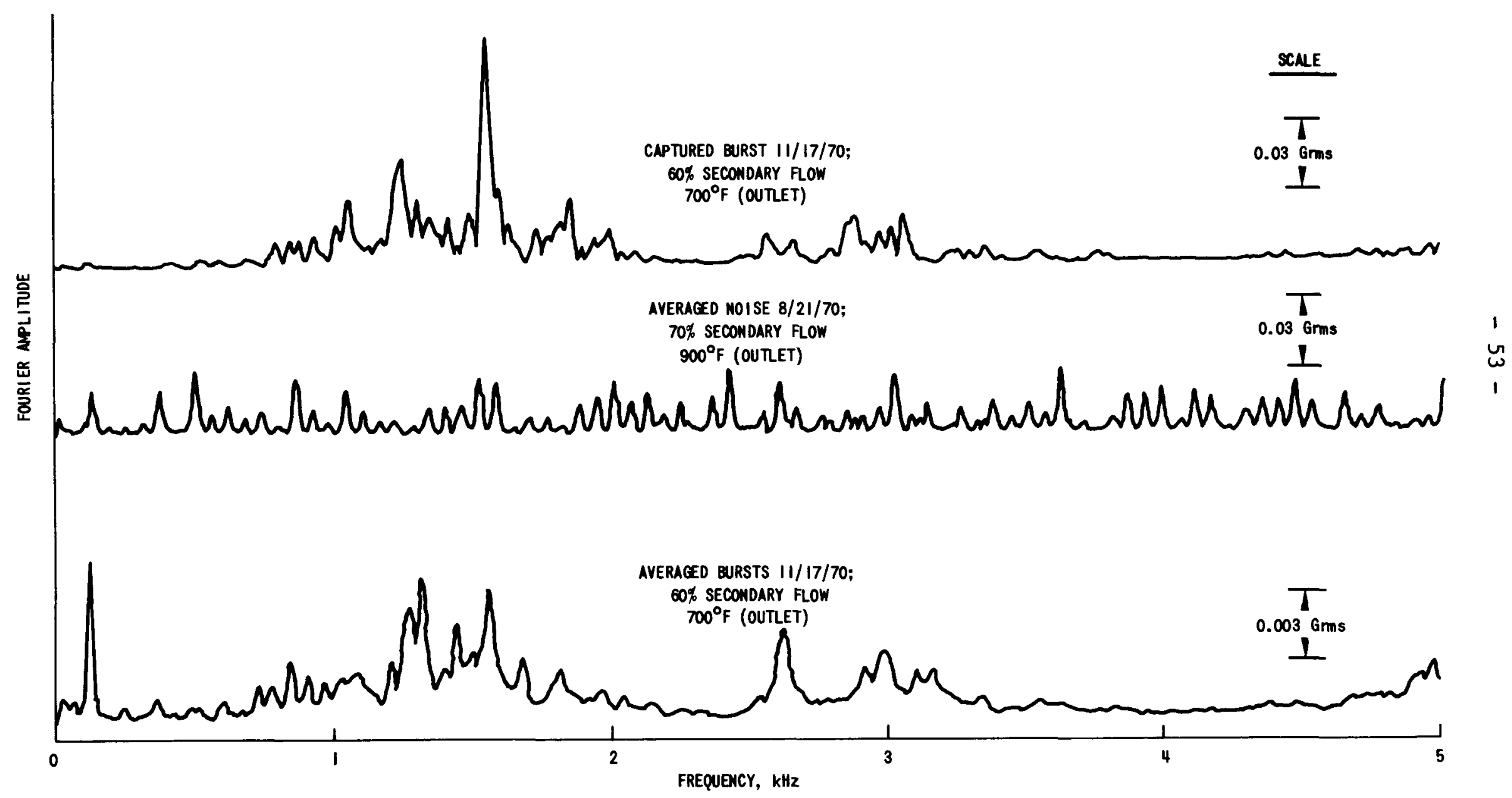

Fig. B-11. Comparison of Noise Burst and Averaged Noise Spectra from IHX 
0

- 
APPENDIX C

\section{Calculation of Vibrations of IHX Drain Tube}

The calculations were made using the equation ${ }^{3}$ for free-vibration resonances $\left(f_{n}\right)$ of a beam:

$$
f_{n}=\frac{\lambda_{n}^{2}}{2 \pi \ell^{2}} \sqrt{\frac{E I}{\rho A}},
$$

where $\lambda_{n}=$ eigenvalues of the system, which are functions of the constraints effective on the beam;

$\ell=$ distance between restraints;

$E$ = modulus of elasticity;

$I$ = area moment of inertia;

$\rho=$ density of the material; and

$A=$ cross-sectional area of the beam.

For fixed-fixed beam ends,

$$
\lambda_{n}=4.73,7.85,11.0,14.1 \ldots \frac{2 n+1}{2} \pi \text { for } n=1,2,3,4 \ldots n \text {. }
$$

For fixed-pinned beam ends,

$$
\lambda_{n}=3.93,7.07,10.2,13.35 \ldots v \frac{4 n+1}{4} \pi \text { for } n=1,2,3,4 \ldots n \text {. }
$$

For the case where sodium is removed from the IHX and both J-clips are removed (Fig. 7 of this report), the following data were used as input for Eq. 1:

$$
\begin{aligned}
\ell & =\text { length of drain tube }=256 \mathrm{in.;} \\
\mathrm{E} & =29 \times 10^{6} \mathrm{lb} / \mathrm{in} .{ }^{2} \text { at } 72^{\circ} \mathrm{F} ; \\
\rho & =\text { density of stainless steel }=7.42 \times 10^{-4} \mathrm{lb}-\mathrm{sec}^{2} / \mathrm{in} \cdot{ }^{4} ; \\
d_{i} & =\text { ID of drain tube }=0.875 \mathrm{in} . ; \text { and } \\
d_{0} & =\text { OD of drain tube }=1.00 \mathrm{in} .
\end{aligned}
$$

Visual observation of the drain tube in free vibration showed the preferred mode of vibration to be in the plane perpendicular to the plane containing the pipe bend. The calculations reported were based on this plane. Use of the higher vibrational modes (as defined by Eq. 1) in both the measurements and the calculations provides a much better picture of the phenomena than use of only the fundamental mode. 
For the case (Fig. 9) where the IHX is filled with sodium (and the noise is generated by flowing sodium), the following data were used as input for $\mathrm{Eq} \cdot 1$ :

$$
\begin{aligned}
& \ell_{1}=\text { distance between the top of the drain tube and the upper } \\
& \text { J-clip }=78-1 / 2 \text { in.; } \\
& \ell_{2}=\text { distance between the upper } \mathrm{J} \text {-clip and point where the pipe is } \\
& \text { fixed to the stand penetrating the baffles }=177-1 / 2 \text { in.; } \\
& \mathrm{E}=26.8 \times 10^{6} \mathrm{lb} / \mathrm{in} .{ }^{2} \text { at } 600^{\circ} \mathrm{F} \text {; } \\
& \rho_{\text {ss }}=\text { density of stainless steel }=7.42 \times 10^{-4} 1 \mathrm{~b}-\mathrm{sec}^{2} / \mathrm{in} .^{4} \\
& \text { (same as } \rho \text { in first case); } \\
& \rho_{\mathrm{Na}}=\text { density of sodium }=8.1 \times 10^{-5} 1 \mathrm{~b}-\sec ^{2} / \mathrm{in} .^{4} \text {; } \\
& \mathrm{d}_{i}=\mathrm{ID} \text { of drain tube }=0.875 \mathrm{in} \text {. (same as in first case); and } \\
& \mathrm{d}_{\mathrm{O}}=\mathrm{OD} \text { of drain tube }=1.00 \mathrm{in} \text {. (same as in first case). }
\end{aligned}
$$

The density actually used in Eq. 1 was a pseudo-density which took into account the immersion of the drain pipe in the liquid sodium. In the equation, $\rho \mathrm{A}$ was replaced by

$$
\rho_{\mathrm{Na}} \mathrm{A}_{\mathrm{O}}+\rho_{\mathrm{Ss}} \mathrm{A}_{\mathrm{SS}}
$$

where $\mathrm{A}_{S S}=$ cross-sectional area of the drain tube; and

$A_{0}=\frac{\pi}{4}\left(d_{0}^{2}+d_{i}^{2}\right)$, which accounts for the sodium set in motion by the pipe vibration. The computed and measured resonances for this case are presented in Figures 9 and 10 and Table I of this report.

This latter configuration is not as simple as the one for the empty IHX. It involves many approximations, such as:

(1) Representation of the pipe and sodium as a free system. Actually (a) the sodium provided a viscous damping effect and (b) the drain tube was continuously being excited by the sodium flow and was dissipating energy in a random manner by contacting the wall of the inlet pipe.

(2) Representation of the upper J-clip as either a fixed or a pinned point. Subsequent investigation has shown that the upper clip was loose and allowed the drain tube to rub radially against it. 
(3) Assumption that the upper section of the tube acted solely as a stiff transmitter rather than as a flexing member. This approximation. becomes complicated and uncertain near resonance modes of the upper section of the tube.

The calculated resonance modes for the pinned-fixed condition of the lower portion of the tube correlate reasonably well with measured modes at all flows of the secondary-system except zero flow, and appear to be flow-dependent. 


\section{REFERENCES}

1. J. S. Bendat and A. G. Piersol, Measurement and Analysis of Random Data, John Wiley and Sons, Inc., N.Y. (1966).

2. J. A. Collum, Guide to Vibration Monitoring, Instruments and Control Systems, 41 (11), 107-110 (November 1968).

3. W. Flügge, Handbook of Engineering Mechanics, pp. 61-8 and 61-9, McGraw-Hill Book Company Inc., N.Y. (1962).

4. C. W. Andrews, Effect of Temperature on the Modulus of Elasticity, Metal Progress 58 (1), 85-100 (July 1950). 